Check for updates

Cite this: RSC Adv., 2017, 7, 26513

Received 4th December 2016 Accepted 19th April 2017

DOI: $10.1039 / c 6 r a 27743 h$

rsc.li/rsc-advances

\title{
Investigation of the tribochemical interactions of a tungsten-doped diamond-like carbon coating (W-DLC) with formulated palm trimethylolpropane ester (TMP) and polyalphaolefin (PAO)
}

\author{
Rehan Zahid, (D)*ab Masjuki Bin Haji Hassan, ${ }^{\star a}$ Abdullah Alabdulkarem,
Mahendra Varman, ${ }^{\mathrm{c}}$ Riaz Ahmad Mufti, ${ }^{\mathrm{b}}$ Md. Abul Kalam, ${ }^{a}$ Nurin Wahidah Binti Mohd

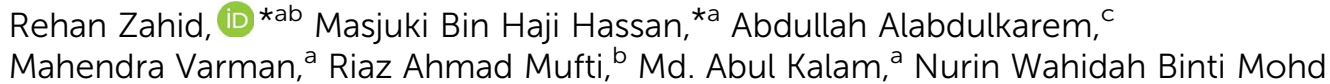 \\ Zulkifli, ${ }^{\mathrm{a}}$ Mubashir Gulzar ${ }^{\mathrm{ab}}$ and Tom Lee ${ }^{\mathrm{a}}$
}

\begin{abstract}
Modern day industrial applications involve rigorous operating conditions, which include high temperature, heavy applied loads, and starved lubrication conditions. In these scenarios, either the lubricant slips out of the contact or only a thin layer of lubricant resides between interacting surfaces. The deposition of diamond-like carbon (DLC) coatings possessing extreme wear resistance and ultra-low friction characteristics and using lubricants capable of physically adsorbing on the interacting surfaces can significantly improve the tribological performance. Due to their superior tribological characteristics, chemically modified vegetable oils, such as palm trimethylolpropane ester (TMP), are one of the potential candidates to be used as lubricant base-oils. To prove the suitability of TMP and DLC coatings for applications involving a boundary-lubrication regime, a logical step forward is to investigate their tribological characteristics in combination with conventional lubricant additives. In this study, the extreme pressure characteristics of TMP formulated with glycerol monooleate (GMO), molybdenum dithiocarbamate (MoDTC), and zinc dialkyldithiophosphate (ZDDP) in combination with steel/steel contact were investigated using a four-ball wear tester. In addition, the tribochemical compatibility of the abovementioned additives with TMP and a tungsten-doped diamond-like carbon coating (W-DLC) was also analyzed using a universal wear testing machine. For comparison, additive-free and formulated versions of polyalphaolefin (PAO) were used as a reference. Moreover, various surface characterization techniques were used to investigate the mechanisms responsible for a particular tribological behavior. TMP-based lubricants exhibited superior extreme pressure characteristics and friction performance as compared to those containing PAO. An improvement in the tribological performance was observed when W-DLC-coated surfaces were used instead of uncoated-surfaces irrespective of the lubricant formulation.
\end{abstract}

\section{Introduction}

The lubricants industry is expected to realize a growth of $2.0 \%$ every year and the worldwide consumption of lubricants will reach approximately 45.4 million metric tons by the year $2019 .^{1}$ The main constituents of commercially available lubricants are base-oils and additive packages (friction modifiers, antiwear/ extreme pressure additives, viscosity modifiers etc.). About $85 \%$ of the lubricants consumed worldwide are derived from

${ }^{a}$ Center for Energy Sciences, Department of Mechanical Engineering, University of Malaya, 50603, Kuala Lumpur, Malaysia. E-mail: rehanzahid.87@gmail.com; masjuki@um.edu.my; Tel: +60-17-6990842; +60-3-79675245

${ }^{b}$ School of Mechanical and Manufacturing Engineering, National University of Sciences and Technology, Sector H-12, 4400O, Islamabad, Pakistan

${ }^{c}$ Mechanical Engineering Department, College of Engineering, King Saud University, 11421 Riyadh, Saudi Arabia non-renewable and non-biodegradable sources such as petroleum [American petroleum institute (API) Group I, II, and III], whereas the rest of them are either synthetic (API Group IV) or bio-based (API Group V)., ${ }^{2,3}$ To meet the energy needs of a rapidly developing world, fossil fuel reserves are depleting at a rapid pace and are on the verge of scarcity. ${ }^{4}$ Moreover, there are many environmental and health issues associated with the excessive use of petroleum-based fuels and lubricants, which include air pollution, soil contamination, and difficult waste management. ${ }^{5}$ Therefore, there is a need to reduce our reliance on conventional lubricants and shift towards environmentally sustainable, renewable, and biodegradable lubricants. ${ }^{6}$

A considerable improvement in the tribological performance of mechanical components operating under a boundarylubrication regime can be achieved by depositing hard coatings such as diamond-like carbon (DLC) coatings. ${ }^{7}$ These 
coatings possess a unique combination of properties with the help of which the friction-induced energy and material losses can be minimized even under starved lubrication conditions. ${ }^{8}$ The lubricity of the DLC coatings can be further enhanced using lubricants such as vegetable oils, which can physically adsorb on the interacting surfaces due to their polar components and unsaturated structure., ${ }^{9,10}$ Although vegetable oils have tribological characteristics (lubricity, flash point, viscosity index, and evaporative losses) comparable to conventional base-oils, they also have some deficiencies. ${ }^{\mathbf{4}, \mathbf{1 1}-13}$ Some of the undesirable properties of vegetable oils include oxidation instability, inferior lowtemperature characteristics, and thermal instability. ${ }^{\mathbf{1 4}}$ These shortcomings originate due to the presence of carbon-carbon double bonds in their structure, which react with atmospheric oxygen and cause degradation. ${ }^{15}$ To decrease the inherent unsaturation and improve the low temperature properties of vegetable oils, several chemical modification techniques have been used by researchers, which include esterification/transesterification, ${ }^{\mathbf{1 6 - 1 9}}$ estolide formation, ${ }^{20-22}$ epoxidation, ${ }^{23-26}$ and partial hydrogenation of the carbon double bonds..$^{27,28}$

Since lubricant additives are manufactured to synergistically interact with conventional base-oils and optimized to enhance the tribological performance of the metallic surfaces, a number of experimental studies have been carried out by researchers to investigate the tribological compatibility of vegetable oils with conventional lubricant additives in combination with various types of DLC coatings. Kalin et al. ${ }^{\mathbf{1 0}}$ studied the tribological characteristics of a hydrogenated amorphous DLC coating (a$\mathrm{C}: \mathrm{H}$ ) and tungsten-doped DLC coating (W-DLC) using sunflower and paraffinic mineral oil formulated with zinc dialkyldithiophosphate (ZDDP) and amine phosphate additives. They reported enhanced tribological performance of the abovementioned DLC coatings with sunflower-based lubricants due to their unsaturated and polar nature. Moreover, when conventional additives were used, significant improvement in the wear resistance of the DLC coatings was observed as a result of tribochemical interactions. In a similar study, Kalin and his team $^{29}$ observed a $30-50 \%$ reduction in the wear resistance of the a-C:H/a-C:H contacts when amine phosphate and dialkyl dithiophosphate ester were used as additives in sunflower oil. They also reported improved tribological performance of symmetrical a-C:H contacts when the formulated sunflower oils were used instead of mineral oil irrespective of their formulation. In another experimental study, Kržan and his team ${ }^{30}$ reported enhanced wear resistance of W-DLC-coated interacting surfaces with rapeseed oil as compared to that of PAO. They also observed that the $\mathrm{W}$-DLC/W-DLC contacts resulted in lower values of friction coefficients as compared to steel/steel contacts; however, this enhanced friction performance was not because of the additives but actually due to the inherent lubricity of the W-DLC coating. In most of the abovementioned studies, the researchers only used one additive at a time while formulating the lubricants. Since commercial lubricants contain various types of additives, it is very important to consider all the tribologically relevant additives in a single formulation. Moreover, rapeseed and sunflower oils, formulated with conventional additives, were used as biolubricants.
In addition, a few researchers also considered palm oil in combination with the DLC coatings but without conventional additives..$^{5,31,32}$ To address this research gap, there is a need to investigate the tribological characteristics of formulated palm oil-based lubricants with DLC coatings.

Therefore, the main focus of the research presented in this study is to investigate the tribochemical interactions of most widely used lubricant additives [glycerol monooleate (GMO), molybdenum dithiocarbamate (MoDTC), and ZDDP] with palm trimethylolpropane ester (TMP) and tungsten-doped diamondlike carbon coating (W-DLC).

\section{Materials and methods}

\subsection{Synthesis of TMP}

To improve the thermooxidative stability and low-temperature characteristics of palm oil, it was chemically modified using a transesterification process. The chemical equation of the reaction is shown in Fig. 1. During the synthesis of TMP, palm oil was first converted into its methyl ester and then reacted with trimethylolpropane. The rationale for selecting trimethylolpropane [2-ethyl-2-hydroxymethyl-1,3-propanediol] as polyol was its low melting point as compared to that of others. During the transesterification process, the ester (-COOR-) group of palm methyl ester was replaced by the hydroxyl $\left(-\mathrm{OH}^{-}\right)$group of trimethylolpropane. The transesterification reaction was conducted in a $500 \mathrm{~mL}$ three-necked reactor equipped with a reflux condenser, thermometer, and sampling port. The condenser was coupled to a vacuum line with a relief valve, an accumulator, and a vacuum trap. During the synthesis, the reactor was immersed in a temperature-controlled silicon oil bath, and the solution was agitated using a magnetic stirrer. A $200 \mathrm{~g}$ volume of methyl ester and a known amount of trimethylolpropane were placed in the reactor, and the mixture was heated to the operating temperature before the catalyst was added. Vacuum was gradually applied after the addition of the catalyst to avoid spillover of the reaction materials. Sodium methoxide was used as the catalyst because it minimizes the saponification of esters. Samples were obtained at pre-determined time intervals for gas chromatographic analysis of the product yield. After the reaction was completed, the catalyst was separated from the product mixture by vacuum filtration, whereas distillation was conducted to remove the unreacted methyl ester from the final product.

\subsection{Formulation of lubricants}

In this study, TMP and PAO were used as base-oils. Among conventional lubricant additives, GMO, MoDTC, and ZDDP

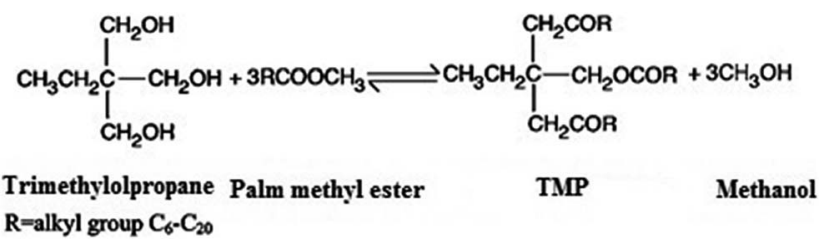

Fig. 1 The chemical equation for the synthesis of TMP. 
were selected to further enhance the tribological performance of the abovementioned base-oils. ${ }^{33}$ Other additives such as detergents, dispersants, and antioxidants were not considered while formulating the lubricants such that the effectiveness of the tribologically relevant additives could be analyzed in isolation. The lubricant additives were acquired from Adeka, Japan, whereas PAO was purchased from Ineos, USA. The formulated versions of TMP and PAO were prepared by adding $3 \mathrm{wt} \%$ of the additives (1.0 $\mathrm{wt} \%$ of GMO, $1.0 \mathrm{wt} \%$ of MoDTC, and $1.0 \mathrm{wt} \%$ of ZDDP) in $97 \mathrm{wt} \%$ of base-oil. The reason for putting all the additives in a single formulation was to investigate whether a synergistic or antagonistic correlation existed between the additives and base-oils when they interacted with the W-DLCcoated sliding surfaces. The formulation details and physicochemical properties of the lubricants are shown in Table 1.

\subsection{Tribological experiments}

2.3.1 Four-ball wear tester. A four-ball wear tester was used to evaluate the extreme pressure characteristics and loadcarrying capacity of the base-oils and formulated lubricants according to the procedures described in the ASTM D-2783 standard. ${ }^{34}$ AISI 52100 steel balls with a diameter of $12.7 \mathrm{~mm}$ and hardness of 64-66 HRC were used to simulate a ball-on-ball geometric configuration. The steel balls and machine components, such as ball holder, clamps, and test-oil cup, were washed with acetone to remove the antirust coatings, contaminants, and residual lubricant layers before and after each test. The extreme pressure characteristics of the lubricants were evaluated by analyzing important wear parameters, including the last non-seizure load (LNSL), initial seizure load (ISL), just before weld load (JBWL), and weld load (WL). The LNSL can be defined as the value of the applied load at which the wear scar diameters (WSDs) of the stationary balls are not higher than 5\% above the compensation line, which consists of the values of the WSD before seizure or weld. The ISL is the value of the applied load at which a significant increase in the WSD is observed due to the momentary breakdown of the lubricating film. The value of the applied load just before welding is called the JBWL, whereas the $\mathrm{WL}$ is the lowest value of the applied load at which welding of the balls occurs. For each lubricant, a series of sliding tests was performed starting with an initial load of $40 \mathrm{~kg}$ under Hertzian contact loading. After this, load was increased until welding of the balls occurred. Each test was conducted twice for a duration of 10 seconds at room temperature where the rotational speed of the top ball was maintained at $1760 \mathrm{rpm}$. The WSDs of the stationary balls were measured for each load using a peripheral microscope to quantify the effectiveness of the lubricant in carrying the applied load.

2.3.2 Universal wear testing machine. Reciprocatory sliding tests were conducted using a universal wear testing machine (Cameron Plint TE99) with a pin-on-plate geometric configuration (Fig. 2). AISI 52100 steel plates with a length, width, and height of $100 \mathrm{~mm}, 30 \mathrm{~mm}$, and $5 \mathrm{~mm}$, respectively, were used as flat surfaces, and BS 1452 cast iron pins with a diameter and length of $10 \mathrm{~mm}$ were used as the counterbodies. The average surface roughness $R_{\mathrm{a}}$ value of the interacting surfaces was 0.05$0.07 \mu \mathrm{m}$, whereas the hardness of the plates and pins were 64-66 HRC and 22-32 HRC, respectively. To evaluate the tribological compatibility of the conventional additives with the TMP and WDLC coating, the friction and wear coefficients of the symmetrical W-DLC contacts (W-DLC/W-DLC contacts) obtained using the additive-free and formulated versions of TMP were compared with those of the PAO-based lubricants. In addition, the tribological performance of the abovementioned lubricants on the self-mated W-DLC-coated surfaces (W-DLC/W-DLC contacts) was also compared with those of the steel/cast iron contacts. Moreover, the influence of a ferrous counterbody on the tribochemical interactions between the conventional additives and W-DLC coating was also investigated using a uncoated-cast iron pin on the W-DLC-coated plates. Each tribotest was conducted for 2 hours with an applied load of $615 \mathrm{~N}$, which is equivalent to $700 \mathrm{MPa}$ of Hertzian contact pressure. Other test parameters including the temperature, stroke length, and linear speed were set at $90^{\circ} \mathrm{C}, 10 \mathrm{~mm}$, and $0.04 \mathrm{~m} \mathrm{~s}^{-1}$, respectively. Before each test, the plates and balls were cleaned with acetone in an ultrasonic bath, whereas the surfaces were washed with cyclohexane and placed in a desiccator before carrying out the surface analysis. Each test was conducted twice to confirm the repeatability and reproducibility of the results and calculate the standard deviations.

\subsection{Deposition of the W-DLC coating}

Since DLC coatings are considered to be chemically inert due to their low surface energies, they are generally doped with metals,

Table 1 The formulation details and physicochemical properties of the formulated lubricants

\begin{tabular}{|c|c|c|c|c|c|c|c|c|}
\hline \multirow[b]{2}{*}{ Lubricants } & \multicolumn{5}{|c|}{ Formulation details } & \multicolumn{3}{|c|}{ Physicochemical properties } \\
\hline & $\begin{array}{l}\text { TMP conc. } \\
(w t \%)\end{array}$ & $\begin{array}{l}\text { PAO conc. } \\
\text { (wt } \%)\end{array}$ & $\begin{array}{l}\text { GMO } \\
\text { conc. } \\
\text { (wt\%) }\end{array}$ & $\begin{array}{l}\text { MoDTC } \\
\text { conc. } \\
\text { (wt\%) }\end{array}$ & $\begin{array}{l}\text { ZDDP } \\
\text { conc. } \\
\text { (wt\%) }\end{array}$ & $\begin{array}{l}\text { Kinematic viscosity } \\
\text { at } 100^{\circ} \mathrm{C}(\mathrm{cSt})\end{array}$ & $\begin{array}{l}\text { Viscosity } \\
\text { index }\end{array}$ & $\begin{array}{l}\text { Density } \\
\left(\mathrm{g} \mathrm{cm}^{-3}\right)\end{array}$ \\
\hline $\begin{array}{l}\text { Palm trimethylolpropane } \\
\text { ester (TMP) }\end{array}$ & 100 & - & - & - & - & 9.33 & 194.53 & 0.92 \\
\hline Polyalphaolefin (PAO) & - & 100 & - & - & - & 9.85 & 135.45 & 0.84 \\
\hline $\begin{array}{l}\mathrm{TMP}+\mathrm{GMO}+\mathrm{MoDTC}+\mathrm{ZDDP} \\
(\mathrm{T}+\mathrm{G}+\mathrm{M}+\mathrm{Z})\end{array}$ & 97 & - & 1 & 1 & 1 & 9.84 & 193.24 & 0.93 \\
\hline $\begin{array}{l}\mathrm{PAO}+\mathrm{GMO}+\mathrm{MoDTC}+\mathrm{ZDDP} \\
(\mathrm{P}+\mathrm{G}+\mathrm{M}+\mathrm{Z})\end{array}$ & - & 97 & 1 & 1 & 1 & 9.99 & 135.34 & 0.82 \\
\hline
\end{tabular}



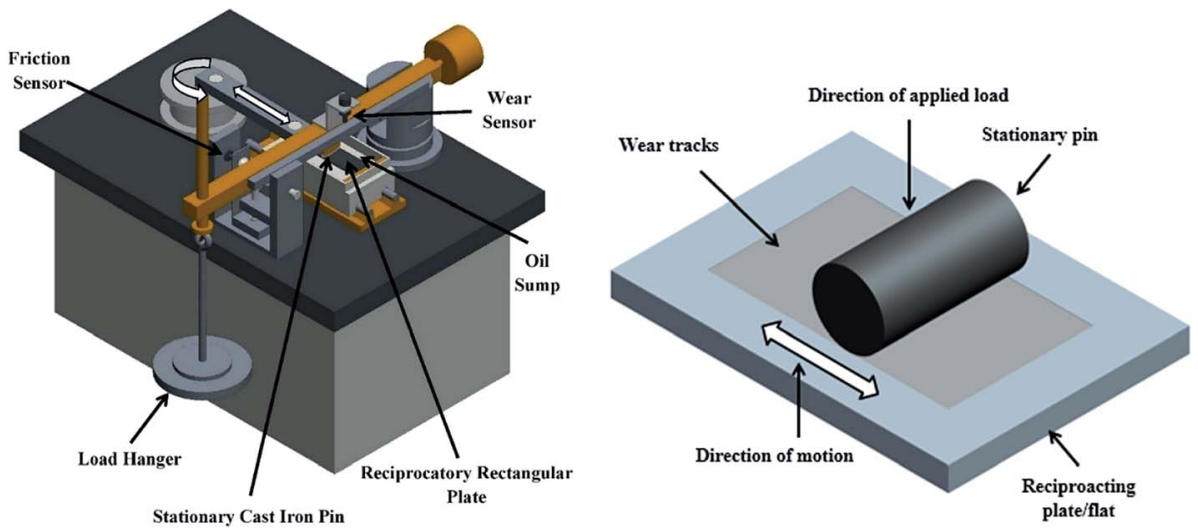

Fig. 2 A labelled 3-dimensional model of the universal testing machine and pin-on-plate geometric configuration.

such as tungsten, to improve their ability to interact with the lubricant additives and environmental species. ${ }^{35}$ In this way, the ultra-low friction, extreme wear resistance, high hardness of the DLC coatings, and chemical reactivity of the metals can be combined in a single material. Due to these reasons, W-DLC was selected, among the various types of DLC coatings, to evaluate its tribological compatibility with conventional additives and TMP. W-DLC is one of the most widely investigated types of DLC coatings and numerous experimental studies have been carried out by researchers on the tribological compatibility of W-DLC coatings with conventional additives..$^{30,36-42}$ As the name suggests, the W-DLC coating falls in the category of doped-DLC coatings.

A physical vapor deposition (PVD) process was used to deposit the tungsten-doped diamond-like carbon (W-DLC) coating with a chromium nitride ( $\mathrm{CrN})$ interlayer on the AISI 52100 steel plates and BS 1452 cast iron pins. Prior to the deposition, the mirror-polished substrates were cleaned with acetone and ethyl alcohol in an ultrasonic bath for 30 minutes and rinsed using distilled water. After this, the substrates were placed on the turntable and loaded into the deposition chamber of PVD sputtering machine where pressure was maintained at 2 $\times 10^{-5} \mathrm{~Pa}$. To evaporate the water molecules, the substrates were heated to $200{ }^{\circ} \mathrm{C}$. Before performing deposition, the surfaces of the substrates were bombarded with $\mathrm{Ar}^{+}$plasma in a glow discharge mode for 30 minutes to remove the contaminants and ferrous oxide layer. The bias voltage was set at $-200 \mathrm{~V}$ during the sputter etching process. The chromium nitride $(\mathrm{CrN})$ interlayer was first deposited on the substrates using ion beam arc evaporation. Nitrogen gas was fed into the deposition chamber via an anode layer ion source where it reacted with chromium ions produced by an arc evaporator with an arc current of $60 \mathrm{~A}$ and deposited as a $\mathrm{CrN}$ interlayer on the substrate surface. Due to its hardness and toughness, the $\mathrm{CrN}$ interlayer provided additional load bearing capacity, enhanced the corrosion resistance of the coated components, and improved the adhesion between the substrate and top W-DLC layer. After the deposition of the $\mathrm{CrN}$ interlayer, the W-DLC coating was deposited on the substrate via ion beam deposition combined with DC magnetron sputtering. A high negative potential was applied to the tungsten target, which was used as the sputtering source, whereas ethyne $\left(\mathrm{C}_{2} \mathrm{H}_{2}\right)$ was used as the reactive gas. A stream of positively charged argon ions was then accelerated towards the tungsten target and bombarded on it to evaporate the tungsten source. A carbon precursor $\left(\mathrm{C}_{2} \mathrm{H}_{2}\right)$ was then introduced into the chamber and it reacted with the sputtered tungsten particles evaporated from the coating material. During the deposition step, the discharge voltage of the ion source and the chamber pressure were set at $330 \mathrm{~V}$ and $0.2 \mathrm{~Pa}$, respectively, whereas the flow rates of argon and ethyne were maintained at 160 standard cubic centimeters per minute (SCCM) and 60 SCCM, respectively. The concentration of tungsten in the W-DLC coating was controlled by the sputtering current of the tungsten target. To keep the thickness of the coating uniform, the substrates were rotated at constant speeds at several axes during the deposition process. In this way, a compact, defect-free, homogenous, and thin layer of the $\mathrm{W}$ DLC coating with the desired composition was deposited on the substrate surface. The total thickness of this coating was approximately 2-3 microns, which also included the 0.1-0.2 $\mu \mathrm{m}$ thick $\mathrm{CrN}$ interlayer. Some of the important properties of the $\mathrm{W}$ DLC coating are listed in Table 2 whereas a schematic of the deposition procedure is shown in Fig. 3.

\subsection{Characterization of the worn surfaces}

To investigate the mechanisms responsible for a particular tribological behavior, the wear tracks on the plates and pins

Table 2 The properties of the W-DLC coating

\begin{tabular}{ll}
\hline Properties & Values \\
\hline Deposition technique & PVD combined with ion sputtering \\
Interlayer & $\mathrm{CrN}$ \\
Thickness & $2-3 \mu \mathrm{m}$ \\
Average surface roughness & $0.05-0.07 \mu \mathrm{m}$ \\
Hardness & $12-15 \mathrm{GPa}$ \\
Young's modulus & $123 \mathrm{GPa}$ \\
Maximum service temperature & $300^{\circ} \mathrm{C}$ \\
Atomic concentration of hydrogen & $15 \%$ \\
Color & Anthracite
\end{tabular}




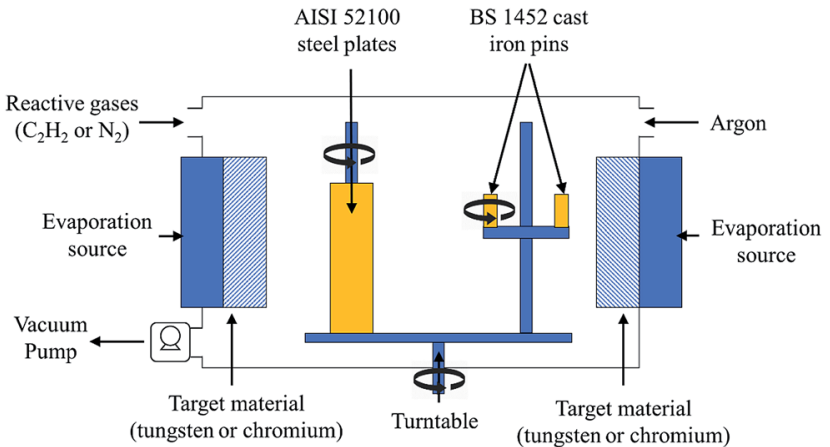

Fig. 3 A schematic of the deposition procedure for the W-DLC coating.

were analyzed using various surface characterization techniques. The width of the wear tracks formed on the W-DLCcoated and uncoated-cast iron pins and wear mechanisms were analyzed using a Zeiss UltraPlus field emission scanning electron microscope (FESEM). The chemical composition of the elements deposited on the pins as a result of the tribochemical interaction with the additives was investigated using an Oxford Instruments energy dispersive X-ray (EDX) analysis system integrated with an FESEM. To study the formation of the tribochemical compounds and quantify the structural transformation of the W-DLC-coated plates from the diamond to graphite phase, Renishaw inVia Raman spectroscopy was used. Moreover, the surface roughness of the plates was measured with the help of the wear track profile data using a Surftest SJ210 mechanical stylus profilometer.

\section{Results}

\subsection{Four-ball wear tester}

3.1.1 Extreme pressure and load carrying capacity. Additive-free TMP exhibited superior extreme pressure characteristics, and the contact was able to sustain higher values of applied load without welding as compared to PAO (Fig. 4a and Table 4). Although LNSL and ISL were the same for both lubricants, the JBWL and WL were $10 \mathrm{~kg}$ higher for TMP as compared to those for PAO (Table 4). At an applied load of $40 \mathrm{~kg}$ and $50 \mathrm{~kg}$, the values of the WSDs obtained with TMP were almost one-half of those obtained with PAO (Fig. 4 and Table 3).
This trend continued when the value of the applied load was further increased; however, the difference in the WSD values obtained with TMP and PAO decreased at heavier loads. The enhanced load-carrying capacity of TMP was attributed to the presence of polar components in its structure. The polar molecules, such as the carboxyl group of the fatty acids, of TMP form a monomolecular layer and attach to the chemically reactive steel surfaces as a result of physisorption. ${ }^{43}$ This thin layer of lubricant separates the contacting surfaces and prevents metal-to-metal contact. Due to the non-polar structure of PAO, this behaviour was not observed in the case of PAO.

Another important conclusion that can be drawn from extreme pressure tribotests is that conventional additives, which are actually optimized for conventional base-oils such as $\mathrm{PAO}$, are also effective in TMP as far as the extreme pressure characteristics are concerned. A significant enhancement in the extreme pressure characteristics of the base-oils was realized when mixed with the additives. At lower values of the applied load (40 kg, $50 \mathrm{~kg}, 63 \mathrm{~kg}$, and $80 \mathrm{~kg}$ ), $\mathrm{P}+\mathrm{G}+\mathrm{M}+\mathrm{Z}$ provided better lubrication to the contact and resulted in lower values for the WSDs as compared to $\mathrm{T}+\mathrm{G}+\mathrm{M}+\mathrm{Z}$. Moreover, LNSL and ISL were also notably high when the formulated version of PAO was used (Table 4). However, $\mathrm{T}+\mathrm{G}+\mathrm{M}+\mathrm{Z}$ was able to provide better load carrying capability in the medium to heavy range of 90-160 $\mathrm{kg}$ of the applied load and exhibited higher values for the JBWL and $\mathrm{WL}$ as compared to $\mathrm{P}+\mathrm{G}+\mathrm{M}+\mathrm{Z}$. In the case of $\mathrm{T}+\mathrm{G}+\mathrm{M}+$ $\mathrm{Z}$, the additives only played their role when applied load was increased beyond $80 \mathrm{~kg}$, whereas the effectiveness of the additives was observed even at an applied load of $40 \mathrm{~kg}$ when mixed with PAO. From these observations, it can be concluded that TMP can be used without additives in these applications that involve low applied loads, whereas its formulated version is more suitable for extreme loading conditions.

\subsection{The universal wear testing machine}

3.2.1 Friction analysis. The transient friction behavior of W-DLC/W-DLC, W-DLC/cast iron, and steel/cast iron contacts in combination with the additive-free and formulated versions of PAO and TMP are shown in Fig. 5, and the average friction coefficient values are presented in Fig. 6. Among base-oils, TMP showed superior friction behavior as compared to PAO irrespective of the sliding surface material. A similar improvement in the friction behavior of symmetrical W-DLC contacts was also
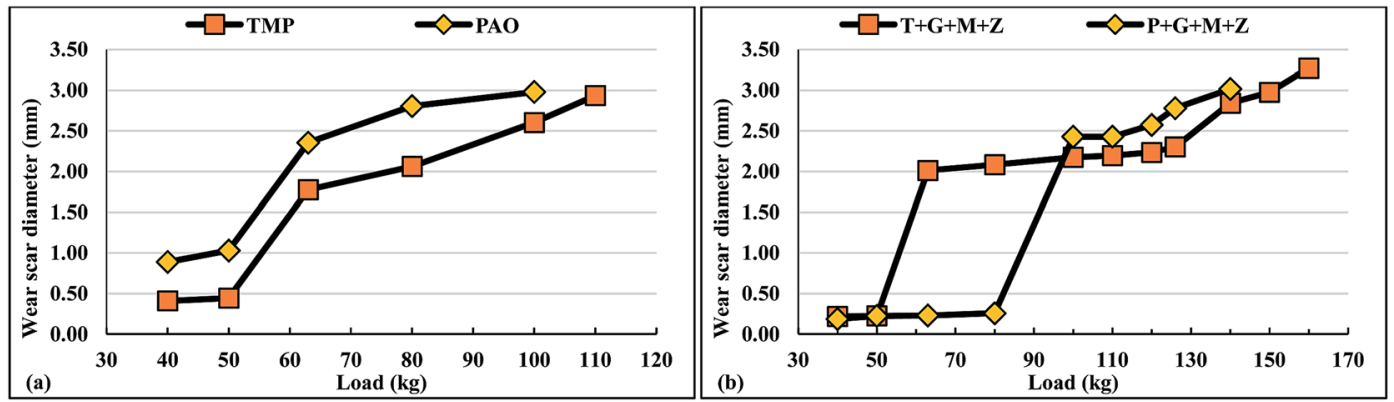

Fig. 4 The average wear scar diameter values plotted against the applied load for the (a) base-oils and (b) formulated lubricants. 
Table 3 The wear scar diameters of individual balls along with the mean values and standard deviations

\begin{tabular}{|c|c|c|c|c|c|c|c|c|c|c|c|c|c|}
\hline \multirow[b]{2}{*}{ Lubricants } & & \multicolumn{12}{|c|}{ Wear scar diameters at different values of the applied load } \\
\hline & & 40 & 50 & 63 & 80 & 100 & 110 & 120 & 126 & 140 & 150 & 160 & 170 \\
\hline \multirow{3}{*}{. } & Ball 2 & 0.407 & 0.437 & 1.764 & 2.082 & 2.629 & 2.935 & & & & & & \\
\hline & Ball 3 & 0.416 & 0.433 & 1.780 & 2.045 & 2.633 & 2.931 & & & & & & \\
\hline & Mean & 0.410 & 0.444 & 1.776 & 2.062 & 2.605 & 2.937 & & & & & & \\
\hline \multirow{4}{*}{ PAO } & Ball 2 & 0.911 & 1.068 & 2.331 & 2.822 & 2.960 & & & & & & & \\
\hline & Ball 3 & 0.873 & 1.022 & 2.331 & 2.809 & 2.994 & & & & & & & \\
\hline & Mean & 0.889 & 1.030 & 2.356 & 2.806 & 2.980 & & & & & & & \\
\hline & Standard deviation & 0.020 & 0.035 & 0.044 & 0.017 & 0.017 & & & & & & & \\
\hline \multirow[t]{2}{*}{$T+G+M+Z$} & Ball 1 & 0.223 & 0.227 & 1.990 & 2.100 & 2.158 & 2.199 & 2.235 & 2.268 & 2.844 & 2.927 & 3.267 & Weld \\
\hline & Ball 2 & 0.218 & 0.223 & 2.011 & 2.083 & 2.205 & 2.206 & 2.243 & 2.268 & 2.876 & 2.986 & 3.368 & \\
\hline & Ball 2 & 0.181 & 0.226 & 0.231 & 0.248 & 2.457 & 2.457 & 2.599 & 2.784 & 3.051 & & & \\
\hline & Ball 3 & 0.193 & 0.216 & 0.235 & 0.265 & 2.410 & 2.410 & 2.578 & 2.815 & 3.002 & & & \\
\hline & Mean & 0.187 & 0.223 & 0.230 & 0.257 & 2.429 & 2.429 & 2.573 & 2.781 & 3.017 & & & \\
\hline & Standard deviation & 0.006 & 0.006 & 0.006 & 0.009 & 0.025 & 0.025 & 0.028 & 0.037 & 0.030 & & & \\
\hline
\end{tabular}

Table 4 The LSNL, ISL, JBWL, and WL observed for the base-oils and formulated lubricants

\begin{tabular}{lllll}
\hline Lubricants & LNSL $(\mathrm{kg})$ & ISL $(\mathrm{kg})$ & JBWL $(\mathrm{kg})$ & WL $(\mathrm{kg})$ \\
\hline TMP & 50 & 63 & 110 & 120 \\
PAO & 50 & 63 & 100 & 110 \\
T + G + M + Z & 50 & 63 & 160 & 170 \\
P + G + M + Z & 80 & 100 & 140 & 150
\end{tabular}

observed by Kalin et al. and Kržan et al. when they used sunflower oil and rapeseed oil instead of paraffinic mineral oil, respectively. ${ }^{10,30}$ As abovementioned, this improved friction characteristic of TMP can be attributed to its polar nature due to which it adsorbs on the interacting surface; however, this behavior is not associated with PAO due to its non-polar chemical structure. It is mentioned in the literature that the polar functional groups in the triglyceride structure of vegetable oils have the ability to strongly adsorb on metallic surfaces. ${ }^{30}$
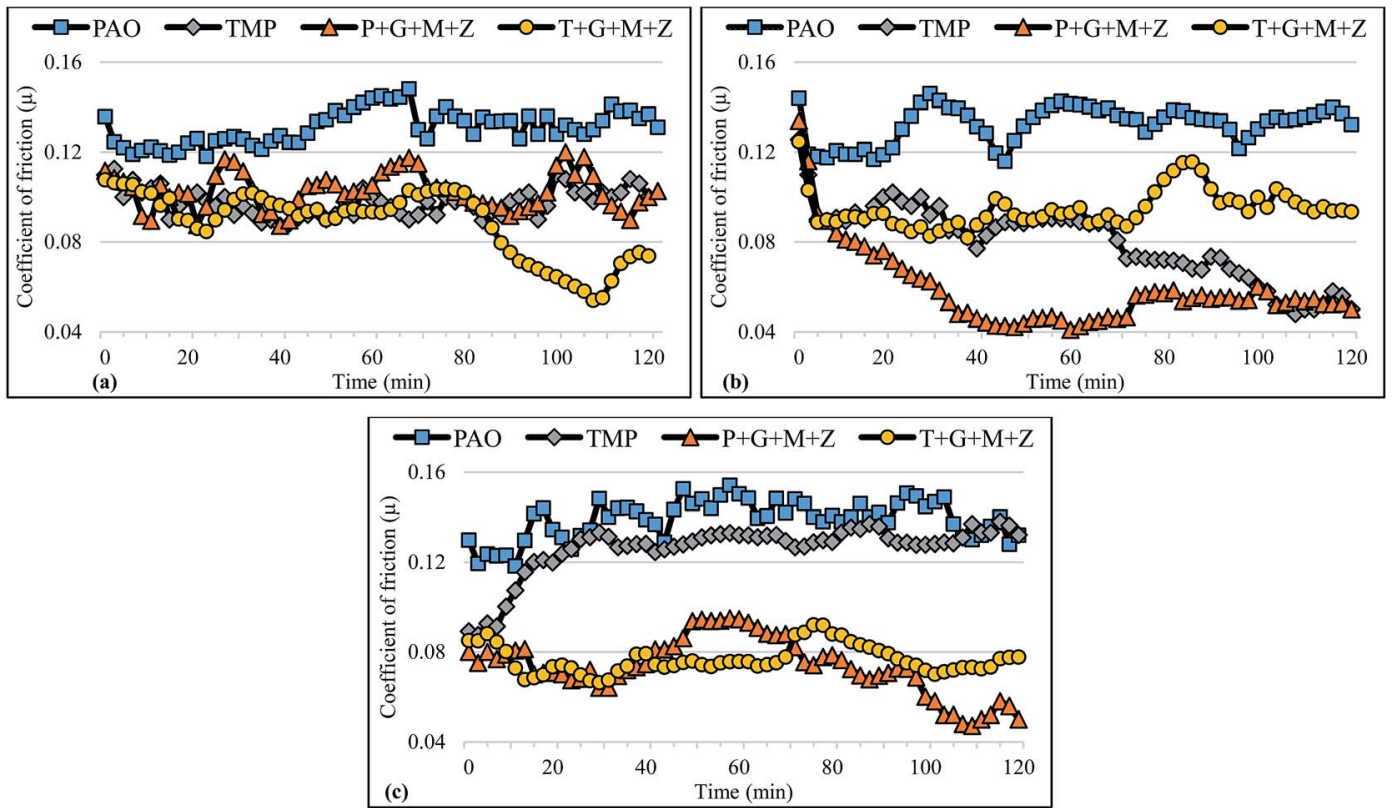

Fig. 5 The transient friction behavior of the (a) W-DLC/W-DLC, (b) W-DLC/cast iron, and (c) steel/cast iron contacts in combination with the PAO and TMP-based lubricants. 


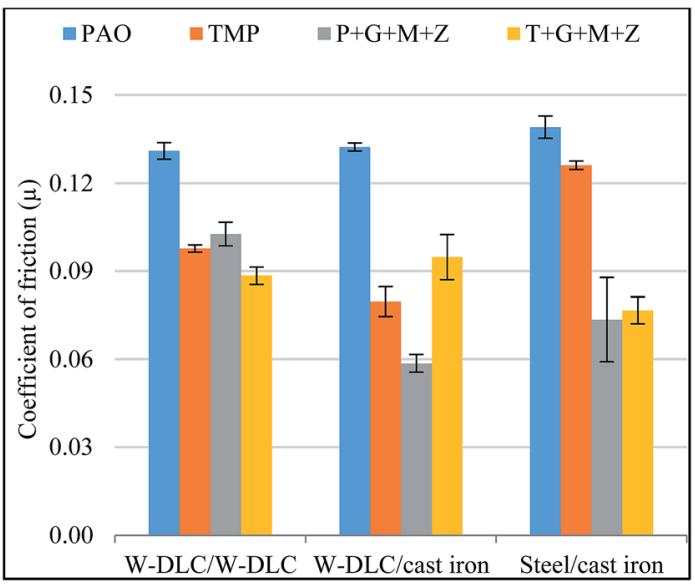

Fig. 6 The average friction coefficient values obtained for the W-DLC/ W-DLC, W-DLC/cast iron, and steel/cast iron contacts in combination with the PAO and TMP-based lubricants.

When the average friction coefficient values of the contacts considered in this study were compared, it was found that the W-DLC/cast iron contacts demonstrated enhanced friction performance as compared to the others. Among the base oils, a lowest friction coefficient value of 0.08 was observed when TMP was used in the W-DLC/cast iron contact, whereas the steel/cast iron contact resulted in the highest value of 0.14 when additive-free PAO was used as the lubricant.

Moreover, significant improvement in the friction behavior was observed when the formulated lubricants were used. The only exception to this finding was the W-DLC/cast iron contact, which showed deterioration in the friction characteristics when $\mathrm{T}+\mathrm{G}+\mathrm{M}+\mathrm{Z}$ was used as the lubricant instead of the additivefree TMP. The additives were proven to be more effective in reducing the friction between interacting surfaces when mixed with PAO instead of TMP. Although friction was reduced in all the contacts, the most eloquent change was observed in the steel/cast iron contacts. Among the formulated lubricants, the lowest friction coefficient value of 0.06 was observed with the $\mathrm{W}$ $\mathrm{DLC} /$ cast iron contact, whereas the highest value of 0.10 was observed in case of the W-DLC/W-DLC contact both with formulated version of PAO. In Fig. 5, it can be seen that the friction coefficients of most of the contacts were reduced after 2 hours of sliding as compared to the initial values, whereas no such behavior was observed with the additive-free lubricants. The most substantial change was observed in the W-DLC/cast iron contact in the presence of $\mathrm{P}+\mathrm{G}+\mathrm{M}+\mathrm{Z}$ in which the friction coefficient was reduced from 0.14 to 0.05 . This shows that some tribochemical interaction occurred between the interacting surfaces and additives, which resulted in enhanced friction characteristics of the contacts at the end of tribotesting. The improved tribological performance due to the formation of additive-derived tribofilms on various types of DLC coatings has also been confirmed by many researchers. Vengudusamy and his team observed friction reduction in self-mated W-DLCcoated surfaces when they used MoDTC as an additive in the API Group III base-oil (A-III). ${ }^{38}$ A similar behavior was also observed by Tasdemir et al. when they used PAO + GMO and
$\mathrm{PAO}+\mathrm{GMO}+\mathrm{ZDDP}$ as lubricants instead of additive-free PAO in combination with ta-C/ta-C contacts. ${ }^{44}$

3.2.2 Wear analysis. The wear coefficients of the uncoated and W-DLC-coated pins and plates sliding against each other in the presence of the PAO and TMP-based lubricants are presented in Fig. 7. Contrary to the friction results, high values for the wear coefficients were observed with the additive-free TMP as compared to those with PAO irrespective of the interacting surface materials (Fig. 7). The most significant difference in the wear characteristics of additive-free TMP and PAO was observed in the case of the W-DLC/cast iron contacts, and the former resulted in approximately $20 \%$ more wear as compared to the latter (Fig. 7).

On substantially mixing the base-oils with additives, the wear characteristics of all the contacts were improved. Irrespective of the lubricant formulation, the lowest wear coefficient values were observed with the symmetrical W-DLC contacts followed by W-DLC/cast iron and steel/cast iron. This improved wear behavior can be related to the inherent wear resistance of the W-DLC coating, the tribochemical interaction of the interacting surfaces with additives, and/or the suppression of graphitization phenomenon by passivation of the dangling carbon bonds by the additives. ${ }^{45-47}$ In an experimental investigation, Kalin and his team observed enhanced wear behavior of the self-mated W-DLC coating when ZDDP and amine phosphates were used as additives in mineral oil due to the prevention of coating spallation. ${ }^{40,41}$ Vengudusamy et al. observed pad-like tribofilm on the contact, which resulted in the reduced wearing-out of W-DLC-coated surfaces when ZDDPcontaining A-III was used as the lubricant. ${ }^{36}$ To confirm the mechanisms responsible for the reduction in the wearing-out of the interacting surfaces in the presence of formulated lubricants, Raman spectroscopy and FESEM/EDX analysis were carried out and have been discussed in the subsequent sections. Although PAO showed an increase in the wear resistance of the interacting surfaces when formulated with GMO, MoDTC, and ZDDP but not as much as TMP. The formulated lubricants were most effective in the steel/cast iron contacts and reduced the wear coefficients to almost one-third as compared to the baseoils. Note that the pins demonstrated different wear behavior as compared to the plates due to the difference in the levels of the wear coefficients of the pins and plates, which can be clearly seen in Fig. 7. Although the pins resulted in high wear coefficients as compared to the plates, irrespective of the lubricant formulation and interacting surfaces material, the wear trend was the same for both surfaces. Among the formulated lubricants, $\mathrm{T}+\mathrm{G}+\mathrm{M}+\mathrm{Z}$ resulted in lowest wear coefficient value for the pins $(6.21 \mathrm{E}-8)$ in the W-DLC/W-DLC contact, whereas highest value (1.98E-7) was observed when $\mathrm{P}+\mathrm{G}+\mathrm{M}+\mathrm{Z}$ was used as the lubricant in the W-DLC/cast iron contact. However, highest (9.10E-9) and lowest wear coefficient values (3.10E-9) observed for the plates were found in the steel/cast iron contacts lubricated with $\mathrm{P}+\mathrm{G}+\mathrm{M}+\mathrm{Z}$ and $\mathrm{T}+\mathrm{G}+\mathrm{M}+\mathrm{Z}$, respectively.

3.2.3 Raman spectroscopy analysis. DLC coatings comprising a chemical structure in which carbon atoms are bonded with each other in an $\mathrm{sp}^{1}, \mathrm{sp}^{2}$, and/or $\mathrm{sp}^{3}$ 

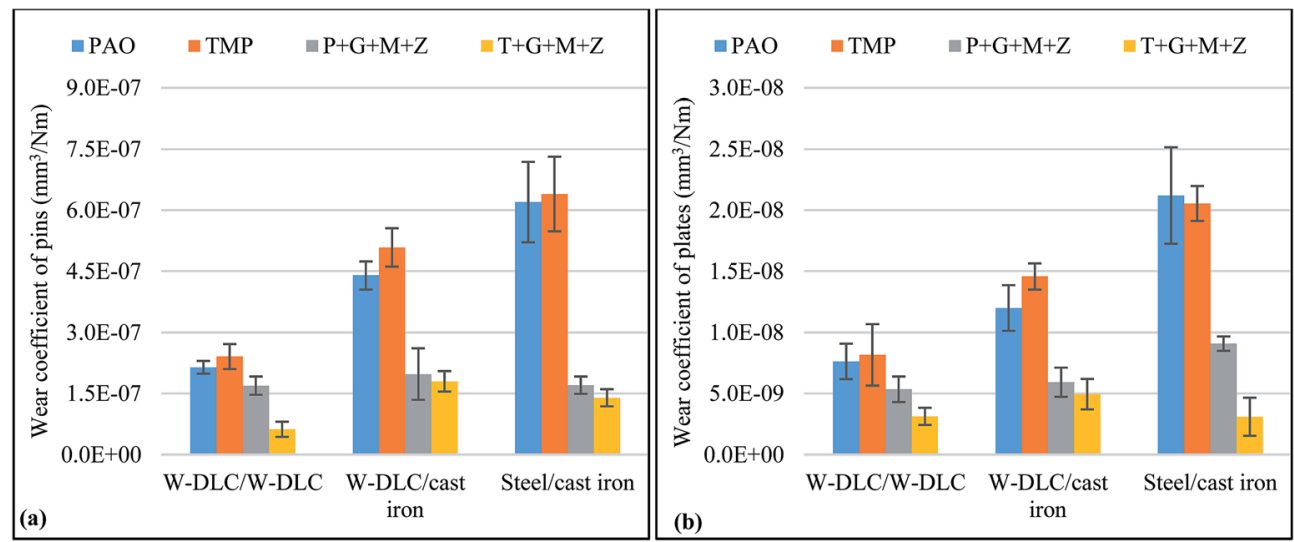

Fig. 7 The wear coefficients of the (a) pins and (b) plates of the W-DLC/W-DLC, W-DLC/steel, and steel/cast iron contacts with PAO and TMPbased lubricants.

configuration. ${ }^{48-50}$ The transformation of the $\mathrm{sp}^{3}$-bonded carbon atoms into $\mathrm{sp}^{2}$-bonded carbon atoms occurs when the interacting surfaces are subjected to extreme operating conditions such as high temperature and heavy loads, and this phenomenon is known as graphitization. ${ }^{47,51,52}$ Graphitization involves structural transformation of the bonded carbon atoms from a diamond to graphite phase and plays a vital role in determining the tribological characteristics of the DLC coatings. Graphitization usually results in decreased friction and facilitates sliding because of low shear strength possessed by the graphitic layer as compared to that possessed by diamond layer. ${ }^{53,54}$ Contrary to this, graphitization has detrimental effects on the hardness and wear resistance of the DLC coatings and both generally decrease with an increase in the degree of graphitization. ${ }^{40,51}$ The formation of a soft graphitic layer makes the surfaces more vulnerable to disintegration, and the overall structure of the coating weakens, resulting in high values for the wear coefficients..$^{55}$ The extent of graphitization can be realized from an increase in the intensity ratio $\left(I_{\mathrm{D}} / I_{\mathrm{G}}\right)$, indicated by the maximum disordered D-peak $\left(I_{\mathrm{D}}\right)$ intensity and the maximum graphite G-peak $\left(I_{\mathrm{G}}\right)$ intensity in the Raman spectra. ${ }^{46}$ The intensity of the D-peaks $\left(I_{\mathrm{D}}\right)$ and G-peaks $\left(I_{\mathrm{G}}\right)$ are usually measured at $1380 \mathrm{~cm}^{-1}$ and $1560 \mathrm{~cm}^{-1}$, respectively. ${ }^{56,57}$

In this study, Raman spectroscopy was carried out on the WDLC-coated plates to identify whether the improved friction performance of the W-DLC/W-DLC and W-DLC/cast iron contacts was due to the inherent low-friction characteristics and self-lubrication ability of the W-DLC coating or the result of graphitization and/or tribochemical interactions between the interacting surfaces and the additives. To quantify the extent of graphitization, broad Raman spectra were acquired in the wavelength range from $800 \mathrm{~cm}^{-1}$ to $2600 \mathrm{~cm}^{-1}$ before and after 2 hours of sliding (Fig. 8-10). Raman spectroscopy was also carried out on the W-DLC-coated plates to obtain narrow scans (100-1300 $\mathrm{cm}^{-1}$ wavelength) for identifying the compounds formed on the contact area as a result of tribochemical interactions between the additives and interacting surfaces (Fig. 11). A Renishaw InVia Raman microscope equipped with a $514 \mathrm{~nm}$ diode laser and $50 \times$ magnification objective lens was used for this purpose. The laser power was set at $10 \%$ to concentrate only on the W-DLC coating and minimize the influence of the substrate material while obtaining the Raman spectra. Other related parameters such as resolution and spectra accumulation and collection time were set at 2400 lines per $\mathrm{nm}$ and 2 and $60 \mathrm{~s}$, respectively. For each surface, three Raman spectra were obtained to achieve a good statistical representation.

When base-oils were used, a decrease in the $I_{\mathrm{D}} / I_{\mathrm{G}}$ ratio and change in the shape of the Raman spectra were observed as compared to those of the as-deposited W-DLC coating. This change can be related to the delamination of the top W-DLC layer from the plates and the influence of the exposed $\mathrm{CrN}$ interlayer and/or steel substrate on the Raman spectra. This hypothesis is also in accordance with the wear coefficient graphs presented in Fig. 7, which show the accelerated wearingout of the interacting surfaces in the presence of base-oils. Since no change in the transient friction behavior of the contacts was seen with the base-oils after 2 hours of sliding (Fig. 5), it can be stated that the delamination of the W-DLC coating was not because of the graphitization phenomenon but actually due to the inability of the lubricants to provide boundary lubrication. The only exception to this finding was the W-DLC/cast iron contact, which showed high extent of graphitization $\left(I_{\mathrm{D}} / I_{\mathrm{G}}=\right.$ $0.967)$ and very low friction coefficient in the presence of the

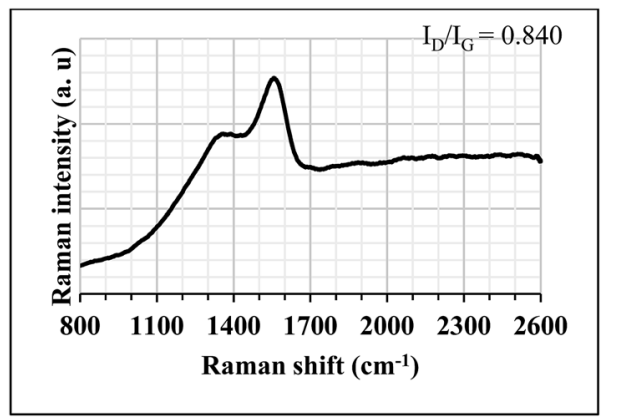

Fig. 8 The Raman spectra of the W-DLC-coated plate before tribotesting. 

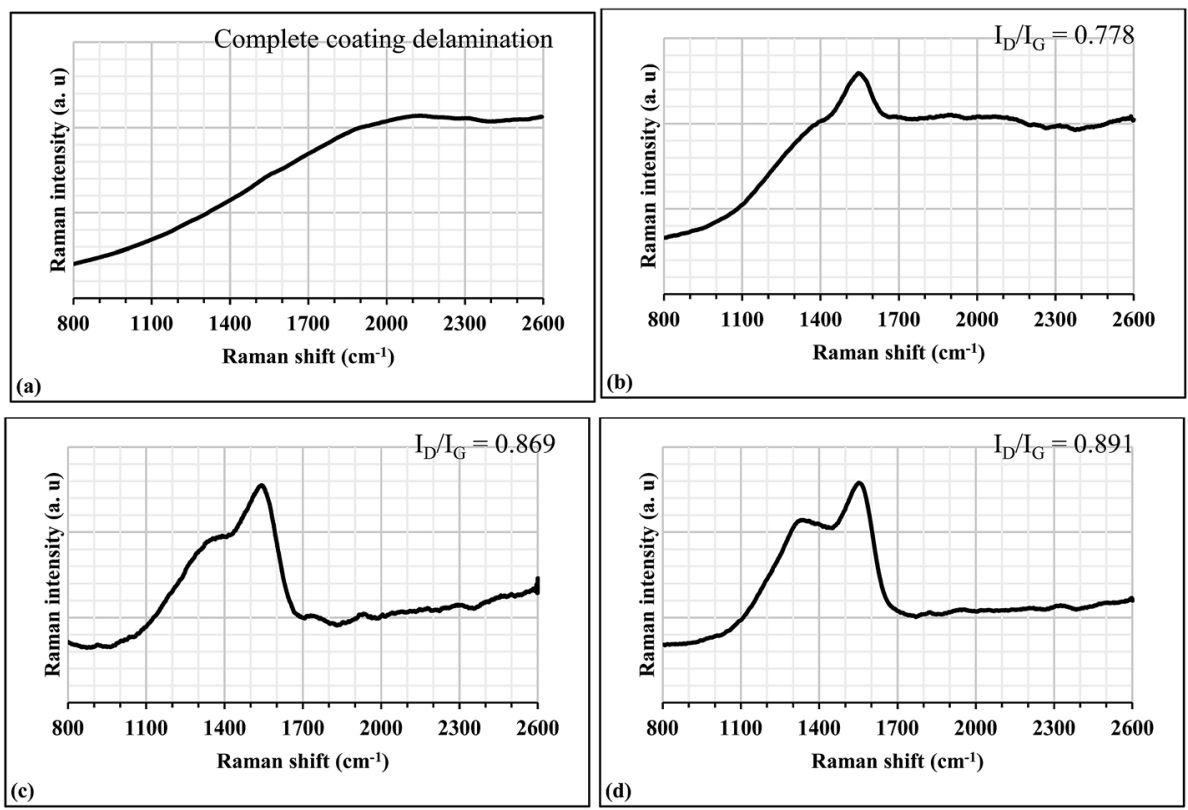

Fig. 9 The Raman spectra of the W-DLC-coated plates after 2 hours of sliding against the W-DLC-coated cast iron pins in (a) PAO, (b) TMP, (c) P $+G+M+Z$, and (d) $T+G+M+Z$.

additive-free TMP (Fig. 6). As a result of graphitization and its adverse effects on the structural integrity of the W-DLC coating, highest wear coefficient value of the plate among the W-DLC/WDLC and W-DLC/cast iron contacts was observed with the additive-free TMP (Fig. 7). The formulation of TMP with additives resulted in reduced wear coefficients for the W-DLC/cast iron contact but the friction between interacting surfaces was substantially increased as compared to additive-free TMP. This behavior can be attributed to the formation of $\mathrm{MoO}_{3}\left(820 \mathrm{~cm}^{-1}\right)$ as a result of the tribochemical decomposition of MoDTC (Fig. 11b). It is mentioned in the literature that $\mathrm{MoO}_{3}$ has a sharp crystalline structure due to which it does not play any role in reducing the friction between interacting surfaces. ${ }^{58}$ Another justification for the deteriorated friction performance of the W-DLC/cast iron contact in the presence of $\mathrm{T}+\mathrm{G}+\mathrm{M}+\mathrm{Z}$ is the suppression of graphitization by the additives, resulting in a decreased $I_{\mathrm{D}} / I_{\mathrm{G}}$ ratio (Fig. 10d). It is widely accepted that additives have the ability to suppress graphitization of the DLC
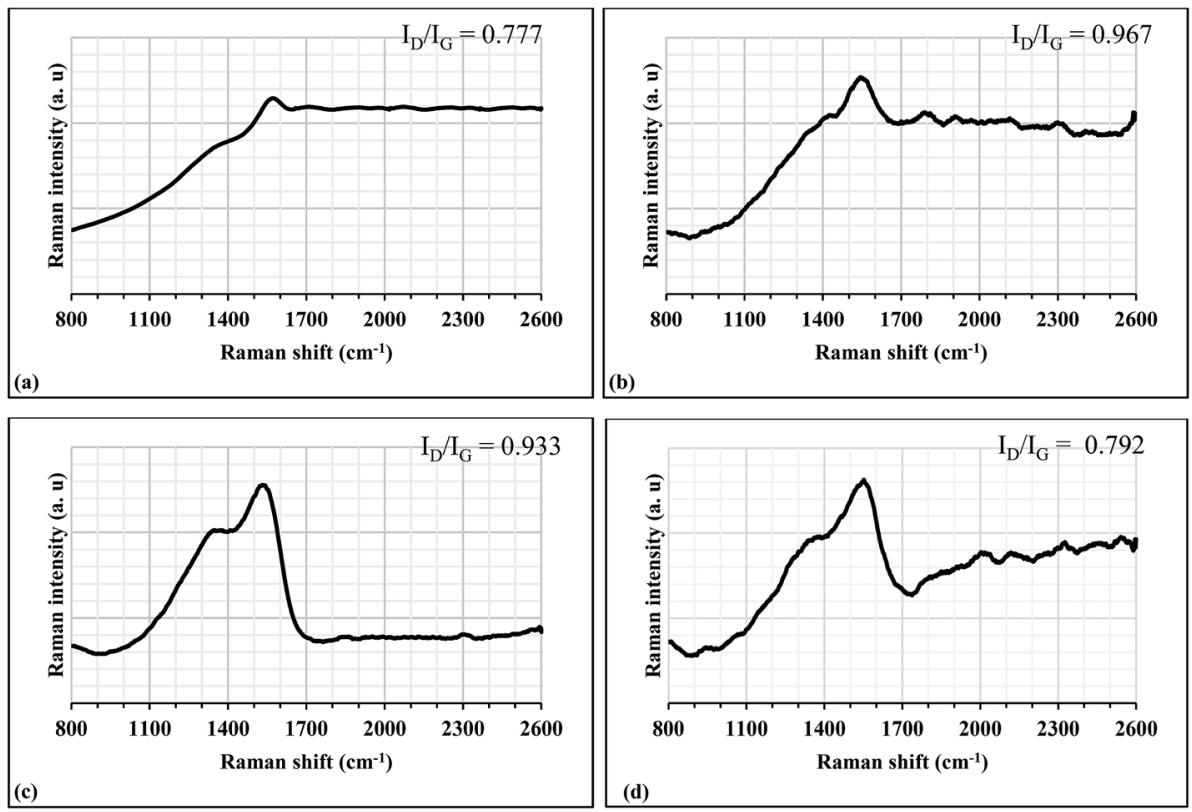

Fig. 10 The Raman spectra of the W-DLC-coated plates after 2 hours of sliding against the uncoated-cast iron pins in (a) PAO, (b) TMP, (c) P + G $+M+Z$, and $(d) T+G+M+Z$. 


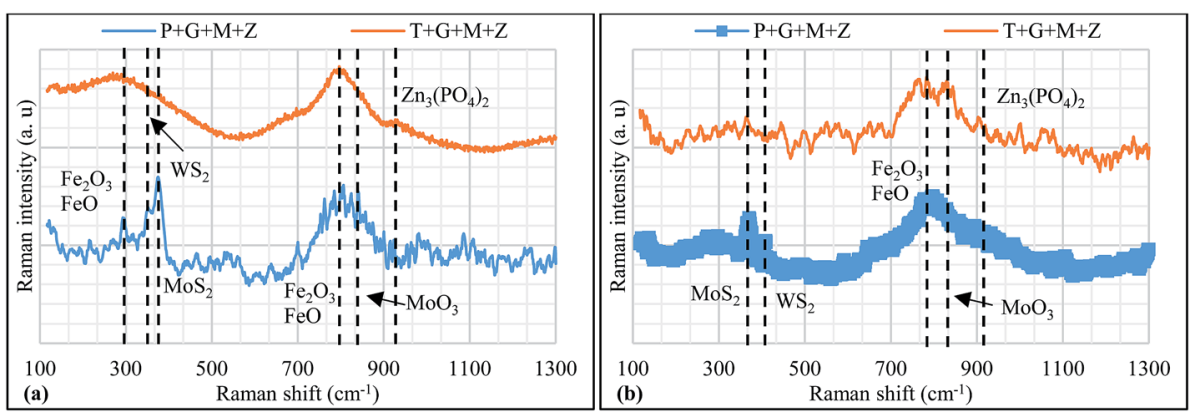

Fig. 11 The narrow Raman spectra of the W-DLC-coated plates after 2 hours of sliding against the (a) W-DLC-coated and (b) uncoated-cast iron pins in combination with the PAO and TMP-based lubricants.

coating by passivating their dangling carbon bonds, resulting in improved wear resistance and increased friction. ${ }^{45-47}$ The suppression in graphitization by the W-DLC coating ( $18 \mathrm{wt} \%$ of tungsten) and an increase in the friction coefficient value from 0.06 to 0.08 was also observed by Vengudusamy and his team when they used A-III + ZDDP as the lubricant instead of additive-free base-oil. ${ }^{42}$ Contrary to $\mathrm{T}+\mathrm{G}+\mathrm{M}+\mathrm{Z}$, increase in the $I_{\mathrm{D}} / I_{\mathrm{G}}$ ratio and the occurrence of the graphitization phenomenon was observed when a formulated version of PAO was used as the lubricant, resulting in lowest friction coefficient value for W-DLC/cast iron contact. Graphitization of the W-DLC coating resulting in decreased friction was also observed by Yue et al. with MoDTC-containing PAO. ${ }^{59}$ The formation of $\mathrm{MoS}_{2}$ and tungsten disulphide $\left(\mathrm{WS}_{2}\right)$, observed at $383 \mathrm{~cm}^{-1}$ and $420 \mathrm{~cm}^{-1}$ in the narrow scans, respectively, can be another explanation for the superior friction behavior of $\mathrm{P}+\mathrm{G}+\mathrm{M}+\mathrm{Z}$ as compared to that of the formulated version of TMP (Fig. 11b). These peaks were not observed in the narrow scans of $\mathrm{T}+\mathrm{G}+\mathrm{M}+\mathrm{Z}$. Although graphitization of the W-DLC coating was also observed in the symmetrical W-DLC contacts, it was not of the same extent as in the W-DLC/cast iron contacts. This difference in the extent of graphitization could be one of the reasons for high friction coefficients observed for W-DLC/W-DLC as compared to those for the W-DLC/cast iron contacts. As abovementioned, graphitization usually results in higher wear rates of the interacting surfaces; however, this behavior was not observed in both the W-DLC/W-DLC and W-DLC/cast iron contacts in combination with $\mathrm{P}+\mathrm{G}+\mathrm{M}+\mathrm{Z}$ and $\mathrm{T}+\mathrm{G}+\mathrm{M}+\mathrm{Z}$. Improved wear behavior was seen when the formulated lubricants were used. This can be attributed to the presence of ZDDP, which is primarily an antiwear additive, in the lubricant that results in the formation of a ZDDP-derived tribofilm. ${ }^{60}$ The formation of the ZDDP-derived tribocompounds composed of zinc, sulfur, and phosphorus was also confirmed by the narrow scans and EDX results. In Fig. 11, the Raman peaks at $800 \mathrm{~cm}^{-1}$ and $964 \mathrm{~cm}^{-1}$ can be related to the formation of zinc oxide (ZnO) and zinc phosphate $\left[\mathrm{Zn}_{3}\left(\mathrm{PO}_{4}\right)_{2}\right]$, respectively. ${ }^{61}$

3.2.4 Surface profile results. The surface profiles of the uncoated (steel/cast iron contacts) and W-DLC-coated plates (W-DLC/W-DLC and W-DLC/cast iron contacts) after 2 hours of tribotesting under the lubricated conditions were obtained using a Surftest SJ-210 mechanical stylus profilometer (Mitutoyo, Kanagawa, Japan). For each plate, three measurements were carried out, one at the top, second at the middle, and third at the bottom of the wear track, to obtain statistically representative and repeatable results. The scan length was adjusted to $12.5 \mathrm{~mm}$ such that the topography of the entire wear track width can be measured and the scan speed was set at $0.25 \mathrm{~mm}$ $\mathrm{s}^{-1}$. Average surface roughness $\left(R_{\mathrm{a}}\right)$ values of the plates were calculated using surface profile data, and the data is presented in Fig. 12.

In Fig. 12, it can be seen that the formulated lubricants resulted in lowest values of the average surface roughness, which is in accordance with the wear coefficient results (Fig. 7). Although a decrease in the surface roughness values was observed when the formulated version of PAO was used instead of the additive-free PAO, it was not to the extent as observed for $\mathrm{T}+\mathrm{G}+\mathrm{M}+\mathrm{Z}$. Irrespective of the lubricant formulation, lowest surface roughness values for the W-DLC-coated plates were observed when uncoated-cast iron pins were used as the counterbodies, whereas the uncoated-steel plates resulted in highest values after 2 hours of sliding against the uncoated-cast iron pin. The severe surface deterioration and roughening observed in the uncoated-steel plate can be attributed to the abrasive wear caused by ferrous-based wear debris. Contrary to this, polishing wear was the predominant wear mechanism in the

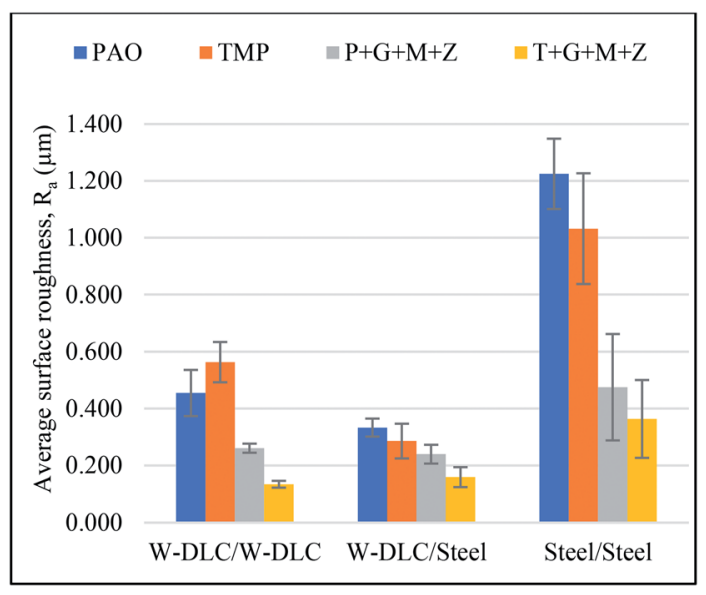

Fig. 12 The average surface roughness values $R_{\mathrm{a}}$ of the uncoated and $W$-DLC-coated plates after 2 hours of sliding in combination with the PAO and TMP-based lubricants. 


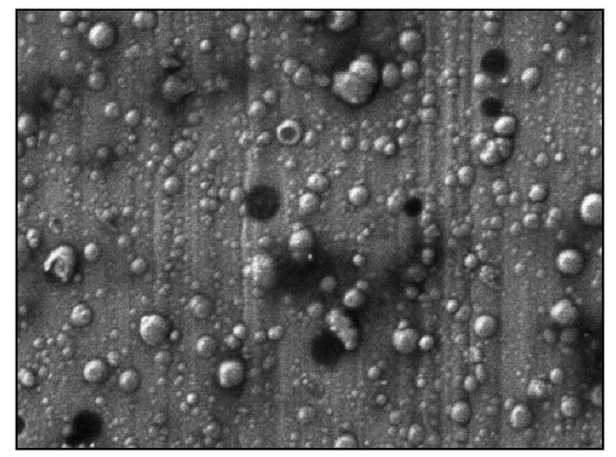

Fig. 13 An SEM image of the as-deposited W-DLC-coated pin.

case of the W-DLC-coated plates. These results demonstrate that the presence of the W-DLC-coated body in a contact prevents the interacting surfaces from excessive deterioration due to its inherent hardness and wear-resistant characteristics. A similar trend in the surface roughness was also seen when the additive-free base-oils were used. The only exception was seen when additive-free TMP was used in combination with the WDLC/W-DLC contact, resulting in higher surface roughness value as compared to that of PAO. As abovementioned, this can be attributed to the inability of the polar molecules and fatty acids of TMP to be adsorbed on the W-DLC-coated surfaces due to their low surface energies and inferior chemical reactivities as compared to ferrous-based materials.

3.2.5 FESEM/EDX analysis. FESEM was used to measure the wear track width and analyze the topography of the uncoated (W-DLC/cast iron and steel/cast iron contacts) and
W-DLC-coated pins (W-DLC/W-DLC contacts). FESEM differs from optical microscopy in a way that it uses a focused beam of electrons instead of photons (light rays) to produce the images of a sample. FESEM was operated at an electron acceleration voltage of $10 \mathrm{keV}$ while obtaining the images and performing EDX analysis such that it acquired the data only from the coating and the electron beam did not penetrate the substrate material.

In Fig. 13, the SEM image of the as-deposited W-DLC-coated pin is presented, and Fig. 14 shows the wear tracks of the WDLC-coated pins after 2 hours of sliding against the W-DLCcoated plates. In these images, three distinct regions can be seen (Fig. 14). In the center, the wear track is shown, whereas the as-deposited W-DLC coated surface can be seen at the top and bottom. The dark lines at the center of the wear track show the CrN interlayer and/or cast iron substrate. In Fig. 14a and c, excessive wear can be seen in the presence of the base-oils, whereas the surfaces are relatively clean in Fig. 14b and d. This improvement in the wear resistance of the coated-pins can be attributed to the presence of additives, which further enhance the tribological behavior of the symmetrical W-DLC contact (Fig. 6 and 7). To confirm whether the coating remains intact after 2 hours of sliding, EDX was carried out, and the results are shown in Table 5. The presence of oxygen, chromium, and nitrogen in large concentrations and small amounts of carbon and tungsten on the coated-pins depicts that most of the top W-DLC coating was either delaminated or wornout after 2 hours of sliding in the presence of PAO. Increase in the oxygen concentration can be attributed to the formation of ferrous oxides when the cast iron substrate was exposed due to
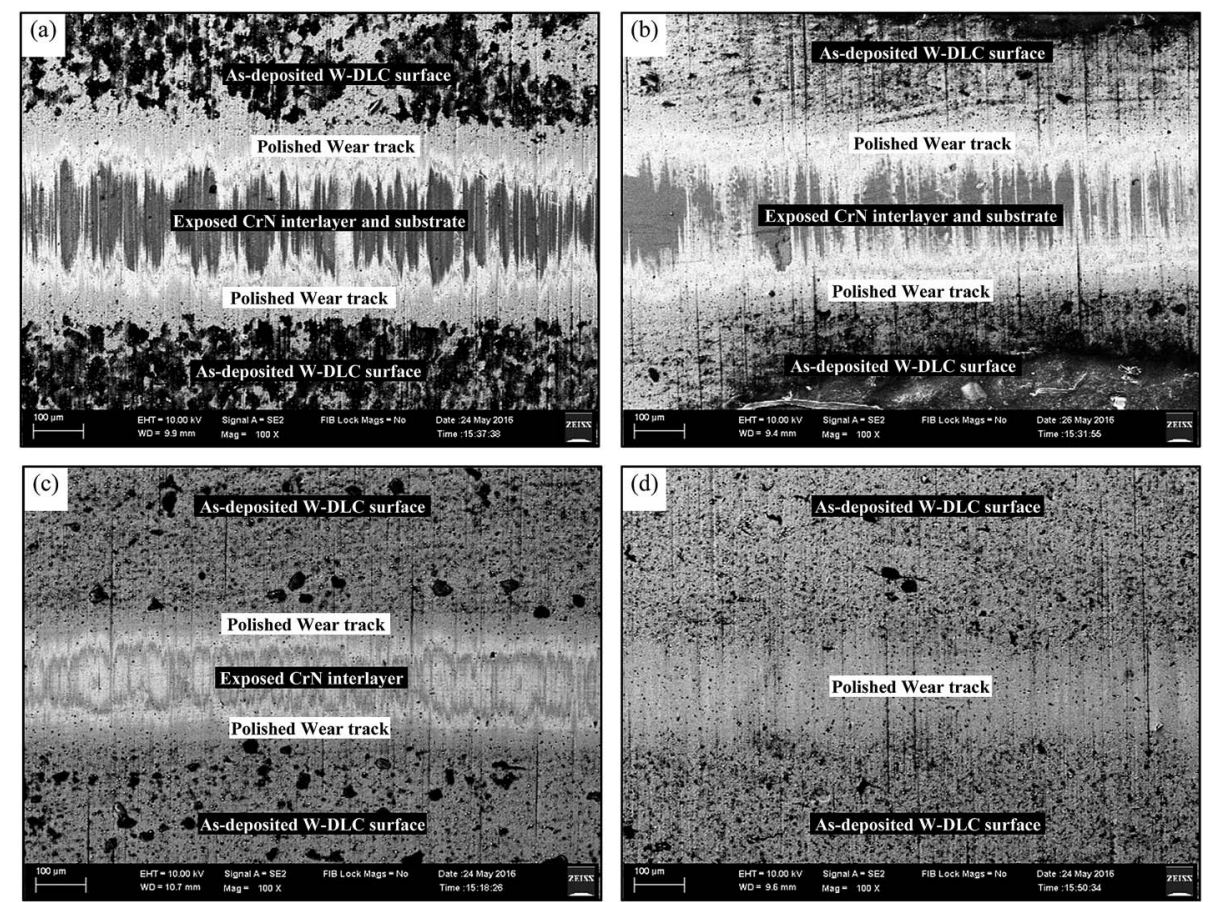

Fig. 14 The wear tracks of the W-DLC-coated pins (W-DLC/W-DLC contact) in combination with (a) PAO, (b) P + G + M + Z, (c) TMP, and (d) T + $G+M+Z$. 
Table 5 The atomic percentage of the elements found on the WDLC-coated pins after 2 hours of sliding against the W-DLC-coated plates using EDX

\begin{tabular}{llrrllllllll}
\hline & \multicolumn{1}{l}{ Elements } & \multicolumn{1}{l}{10} & & & & & \\
\cline { 2 - 10 } Lubricants & $\mathrm{C}$ & $\mathrm{W}$ & $\mathrm{Cr}$ & $\mathrm{N}$ & $\mathrm{P}$ & $\mathrm{S}$ & $\mathrm{Mo}$ & $\mathrm{Zn}$ & $\mathrm{Fe}$ & $\mathrm{O}$ \\
\hline As-deposited & 75.3 & 18.1 & 1.2 & - & - & - & - & - & 1.2 & 4.2 \\
PAO & 12.6 & 2.1 & 37.7 & 23.9 & & & & & 3.8 & 19.8 \\
TMP & 77.5 & 11.2 & 3.6 & 1.1 & - & - & - & - & 1.3 & 5.3 \\
$\mathrm{P}+\mathrm{G}+\mathrm{M}+\mathrm{Z}$ & 46.3 & 12.9 & 18.3 & 8.8 & 0.2 & 1.2 & 1.2 & 0.2 & 2.1 & 8.8 \\
T + G + M + Z & 73.1 & 16.3 & 1.2 & 0.7 & 1.8 & 0.4 & 0.8 & 1.2 & 1.1 & 3.3
\end{tabular}

Table 6 The atomic percentage of the elements found on the uncoated-cast iron pins after 2 hours of sliding against the W-DLCcoated plates using EDX

\begin{tabular}{lllllllllllr}
\hline & \multicolumn{1}{c}{ Elements } & & & & & & & & \\
\cline { 2 - 10 } Lubricants & $\mathrm{C}$ & $\mathrm{W}$ & $\mathrm{Cr}$ & $\mathrm{N}$ & $\mathrm{P}$ & $\mathrm{S}$ & $\mathrm{Mo}$ & $\mathrm{Zn}$ & $\mathrm{Fe}$ & $\mathrm{O}$ \\
\hline $\mathrm{PAO}$ & 16.7 & 0.3 & - & - & 0.3 & 0.1 & - & - & 74.5 & 8.2 \\
$\mathrm{TMP}$ & 25.7 & 2.1 & - & - & 0.3 & 0.2 & - & - & 59.2 & 12.5 \\
$\mathrm{P}+\mathrm{G}+\mathrm{M}+\mathrm{Z}$ & 14.2 & - & - & - & 1.2 & 3.2 & 2.4 & 1.9 & 69.6 & 7.5 \\
$\mathrm{~T}+\mathrm{G}+\mathrm{M}+\mathrm{Z}$ & 13.2 & 0.1 & - & - & 2.1 & 1.3 & 0.8 & 3.4 & 64.5 & 14.4 \\
\end{tabular}

the delamination of the DLC coating. In the case of the TMPbased lubricants, especially $\mathrm{T}+\mathrm{G}+\mathrm{M}+\mathrm{Z}$, iron, chromium, and nitrogen were detected in very small concentrations. This shows that the formulated version of TMP improved the wearresistance of the contact due to which the top layer of the coating was retained after 2 hours of sliding with the exposure of the CrN interlayer at a few remote sites. The mixing of GMO, MoDTC, and ZDDP in PAO also enhanced its inherent wearcharacteristics, and the total delamination of the W-DLC coating was avoided. Although an improvement in the tribological performance of the W-DLC/W-DLC contacts was seen with the formulated lubricants and the formation of MoDTC and ZDDP-derived tribocompounds were detected via Raman spectroscopy, elements such as molybdenum, zinc, sulphur, and phosphorus were not seen in abundance on the W-DLCcoated pin surface as compared to those on the uncoated surfaces (Tables 5-7). A possible justification for this behavior is the making and breaking of a tribofilm during the tribotests due to its weak-adhesion with the W-DLC-coated surfaces. The absence or comparatively small concentration of ferrous-based

Table 7 The atomic percentage of elements found on the uncoatedcast iron pins after 2 hours of sliding against the uncoated-steel plates using EDX

\begin{tabular}{llllllllllll}
\hline & \multicolumn{1}{l}{ Elements } \\
\cline { 2 - 10 } Lubricants & $\mathrm{C}$ & $\mathrm{W}$ & $\mathrm{Cr}$ & $\mathrm{N}$ & $\mathrm{P}$ & $\mathrm{S}$ & $\mathrm{Mo}$ & $\mathrm{Zn}$ & $\mathrm{Fe}$ & $\mathrm{O}$ \\
\hline $\mathrm{PAO}$ & 7.7 & - & - & - & - & - & - & - & 80.1 & 12.3 \\
$\mathrm{TMP}$ & 9.5 & - & - & - & - & - & - & - & 78.2 & 12.3 \\
$\mathrm{P}+\mathrm{G}+\mathrm{M}+\mathrm{Z}$ & 5.2 & - & - & - & 0.4 & 1.2 & 4.3 & 1.4 & 66.6 & 20.9 \\
$\mathrm{~T}+\mathrm{G}+\mathrm{M}+\mathrm{Z}$ & 7.8 & - & - & - & 0.2 & 1.8 & 1.3 & 1.3 & 63.0 & 24.5
\end{tabular}

compounds, such as iron oxide and iron sulphide, which promote binding between the additive-derived tribofilm and contact surface, can be attributed to this weak adhesion. ${ }^{62,63}$ Similar weakly-adhered additive-derived tribofilms were also observed by Equey and his team with a symmetrical a-C:H contact in the presence of PAO + ZDDP. ${ }^{64}$

To analyze the mechanisms responsible for a particular tribological behavior in the W-DLC/W-DLC contacts, magnified SEM images were also obtained at the central regions of the wear tracks and are presented in Fig. 15. In Fig. 15a and c, the bright regions depict the exposed CrN interlayer, whereas the dark regions represent the top W-DLC layer. In the presence of the PAO-based lubricants, clear scratch lines in the direction of sliding can be seen, which result in the removal of the W-DLC coating from certain areas. Plenty of small pits were also formed as a result of abrasive wear. When additive-free PAO was used, ploughing was seen due to the adhesion between W-DLCcoated surfaces, which resulted in deep grooves and exposed ferrous-based substrate material. Contrary to this, delamination of the W-DLC coating was not observed in the presence of the TMP-based lubricants, especially $\mathrm{T}+\mathrm{G}+\mathrm{M}+\mathrm{Z}$, and polishing was the predominant wear mechanism with few shallow scratch lines (Fig. 15b and d). Although some of the $\mathrm{CrN}$ interlayer was exposed due to the abrasive wear of the debris, which resulted in the formation of many micro-pits and ditches on the pin surface, the overall $\mathrm{W}$-DLC coating was able to maintain its integrity over the 2 hours of sliding.

In Table 6, the atomic percentage of elements found on the uncoated-cast iron pins after 2 hours of sliding against the WDLC-coated plates under lubricated conditions is shown. High concentration of carbon was observed on the pin surfaces as compared to the original carbon content of BS 1452 cast iron (2.90-3.65\%). This increase in the carbon concentration can be attributed to either transfer of the coating material from the $\mathrm{W}$ DLC-coated plates or due to the residual lubricant. Since negligible amount of tungsten was observed on pins, it can be stated that no significant transfer of the W-DLC coating occurred. The only exception to this finding was seen when additive-free TMP was used as the lubricant and the coating material was transferred from the plate to the cast iron pin (Fig. 16d). Removal of the W-DLC coating from the plate surface due to the occurrence of graphitization was also confirmed by Raman spectroscopy (Fig. 10). In the case of the W-DLC/cast iron contacts, lowest value of the friction coefficient was observed when $\mathrm{P}+\mathrm{G}+\mathrm{M}+\mathrm{Z}$ was used as the lubricant, followed by TMP, $\mathrm{T}+\mathrm{G}+\mathrm{M}+\mathrm{Z}$, and PAO. The improved friction performance of the $\mathrm{W}$-DLC/cast iron contact in the presence of $\mathrm{P}+\mathrm{G}+\mathrm{M}+\mathrm{Z}$ can be attributed to the tribochemical interactions between the additives and interacting surfaces, resulting in the formation of tribofilms composed of phosphorus, sulphur, molybdenum, and zinc. It is mentioned in the literature that the presence of MoDTC and ZDDP in the lubricant results in decreased friction between interacting surfaces due to the formation of $\mathrm{MoS}_{2} \cdot{ }^{65,66}$ During tribotesting, MoDTC is tribochemically decomposed into $\mathrm{MoS}_{2}$ and $\mathrm{MoO}_{3} \cdot{ }^{65}$ It is believed that $\mathrm{MoS}_{2}$ facilitates the sliding due to its layered structure and low shear strength. ${ }^{8}$ On the other hand, $\mathrm{MoO}_{3}$, instead of 


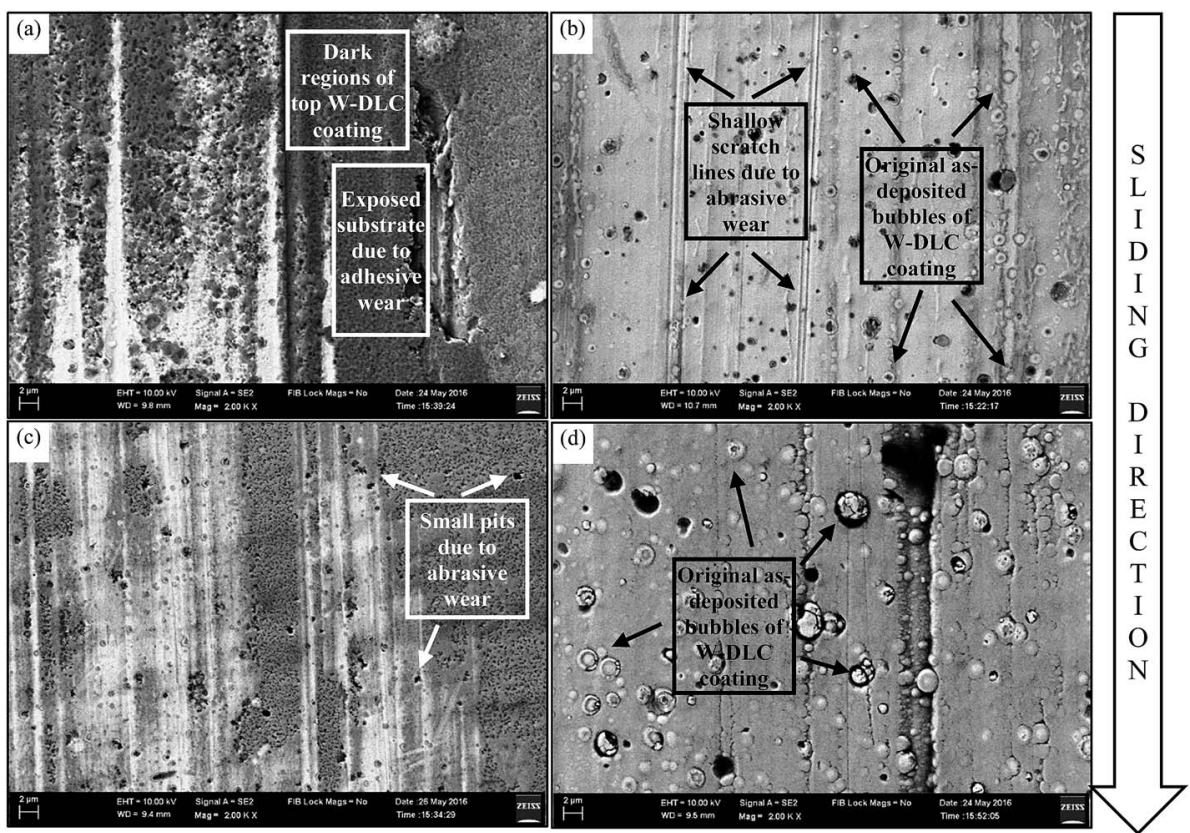

Fig. 15 SEM images of the W-DLC-coated pins (W-DLC/W-DLC contact) in combination with (a) PAO, (b) $T M P,(c) P+G+M+Z$, and (d) $T+G$ $+M+Z$.

reducing the friction coefficient, increases the wearing-out of the interacting surfaces due to its sharp edge crystalline structure. ${ }^{58}$ MoDTC can only play its primary role as a friction modifier if its decomposition results in higher concentration of $\mathrm{MoS}_{2}$ compared to that of $\mathrm{MoO}_{3}{ }^{58}$ If ZDDP is present in the MoDTC-containing lubricant, it supplies sulphur to MoDTC and amplifies the formation of $\mathrm{MoS}_{2} \cdot{ }^{44}$ Contrary to $\mathrm{P}+\mathrm{G}+\mathrm{M}+$ $\mathrm{Z}$, when $\mathrm{T}+\mathrm{G}+\mathrm{M}+\mathrm{Z}$ was used as the lubricant, very small concentration of molybdenum was observed on the pin surface, which showed either very little or no tribochemical interactions between the MoDTC and interacting surfaces. As a result, significant increase in the friction coefficient was observed with $\mathrm{T}+\mathrm{G}+\mathrm{M}+\mathrm{Z}$ as compared to that with additive-free TMP. Contrary to the friction results, an eloquent improvement in the wear behavior of the W-DLC/cast iron contact was observed when the formulated TMP was used instead of its additive-free
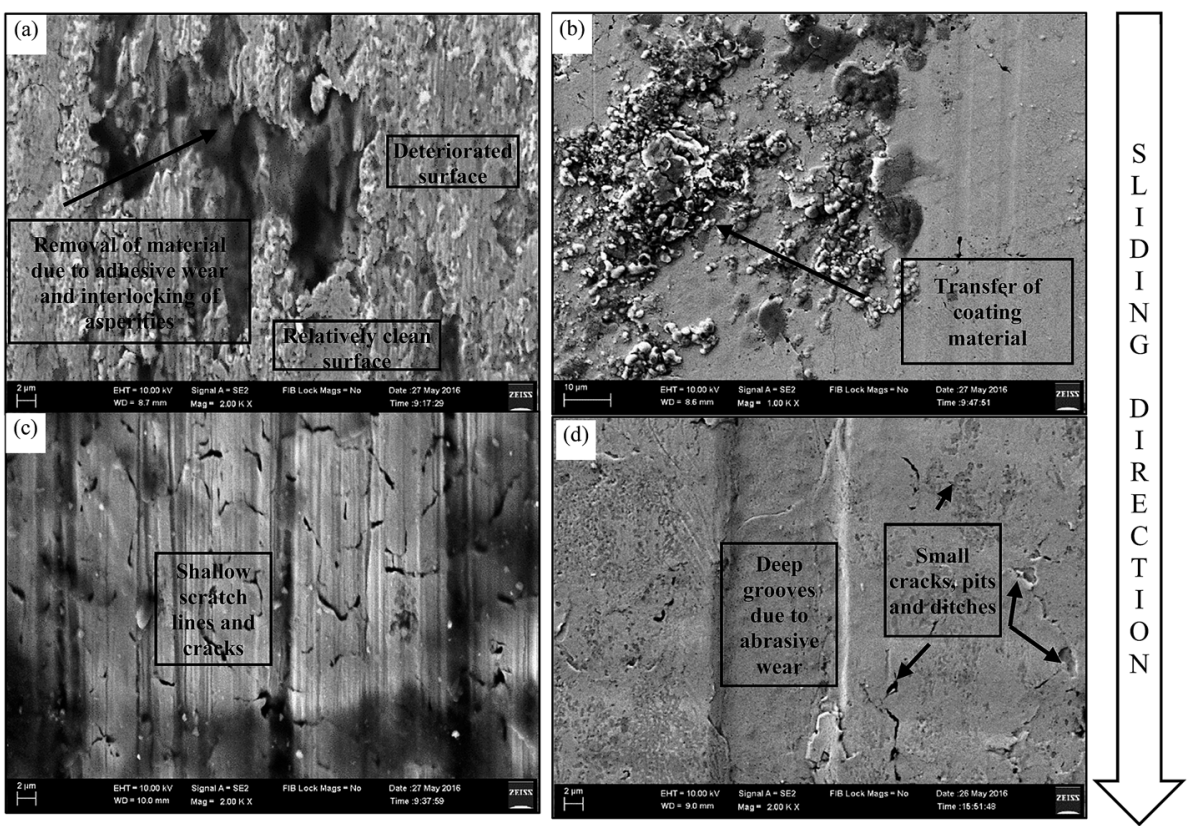

Fig. 16 SEM images of the uncoated-cast iron pins (W-DLC/cast iron contact) in combination with (a) PAO, (b) TMP, (c) P + G + M + Z, and (d) $T+$ $G+M+Z$. 
version. This enhanced wear behavior can be attributed to the formation of ZDDP-derived tribofilm composed of zinc oxide, zinc sulphide, and zinc phosphate on the contact asperities due to which direct metal-to-metal contact was prevented. ${ }^{67}$ Another justification for this behavior was attributed to the hydroxylation of the dangling carbon atoms in the W-DLC coatings by the -OH- group of GMO, resulting in the formation of a monomolecular layer on the interacting surfaces. ${ }^{46} \mathrm{~A}$ similar ZDDP-derived tribofilm and adsorption of the hydroxyl groups of GMO was also observed by Abdullah and his team on various DLC contacts, which resulted in higher levels of friction and reduction in the wearing rate of the interacting surfaces. ${ }^{46,68}$

In Fig. 16, the SEM images of the cast iron pins after 2 hours of sliding against the W-DLC-coated plates are shown. Significant surface deterioration was seen in the presence of PAO, whereas no such effect was seen with other lubricants (Fig. 16a). This degradation can be attributed to the adhesion and interlocking of asperities, which result in the transfer of material from one surface to another. A similar material transfer was also seen when additive-free TMP was used, but it was in the reverse order i.e. carbon was transferred from the W-DLC-coated plate to the cast iron pin (Fig. 16b). This transfer of material results in lowest friction coefficient value of the W-DLC/cast iron contact in combination with the TMP among the base-oils. No signs of adhesive wear and transfer of material were observed when the formulated lubricants were used (Fig. 16c and d). Instead, deep grooves due to abrasion and surface cracking were observed as the main wear mechanisms. Similar cracks on the interacting surfaces were also observed by Zulkifli and his team in the presence of TMP due to localized plastic deformation, which eventually led to spall formation. ${ }^{69}$
The atomic percentages of elements deposited on the uncoated-cast iron pins after 2 hours of sliding against AISI 52100 steel plates are presented in Table 7. Compared to the WDLC/W-DLC and W-DLC/cast iron contacts, higher concentrations of oxygen were observed on the cast iron pins irrespective of the lubricant used. This higher concentration of oxygen was associated with the formation of ferrous oxides $\left(\mathrm{FeO}, \mathrm{Fe}_{2} \mathrm{O}_{3}\right.$, and $\mathrm{Fe}_{3} \mathrm{O}_{4}$ ), which play an important role in the formation and strong adherence of the additive-derived tribofilm to the interacting surfaces. ${ }^{70,71}$ As the oxide layers can be easily removed from the interacting surfaces during sliding, highest wear coefficients were observed with the steel/cast irons contacts when the non-formulated lubricants were used (Fig. 7). On the other hand, the oxides layers play an important role in establishing the tribochemical interactions between the additives and interacting ferrous surfaces, resulting in enhanced tribological behaviour. ${ }^{63,64}$ Another justification for the higher concentration of oxygen, especially in the presence of the formulated lubricants, is the adsorption of the hydroxyl groups of GMO and formation of a highly viscous layer, which not only prevents the surface asperities from coming into direct contact with each other and reduces wear but also facilitates sliding. Significant improvement in the tribological characteristics of the steel/cast iron contact in the presence of the formulated lubricants can also be attributed to the formation of the MoDTC and ZDDP-derived tribofilms, which not only prohibits the surfaces from excessive wearing but also results in improved friction performance.

SEM images of the cast iron pins after 2 hours of sliding against the steel plates are presented in Fig. 17. When the additive-free lubricants were used, severe cracks, wear debris, deep grooves, and structural disintegration was observed on the

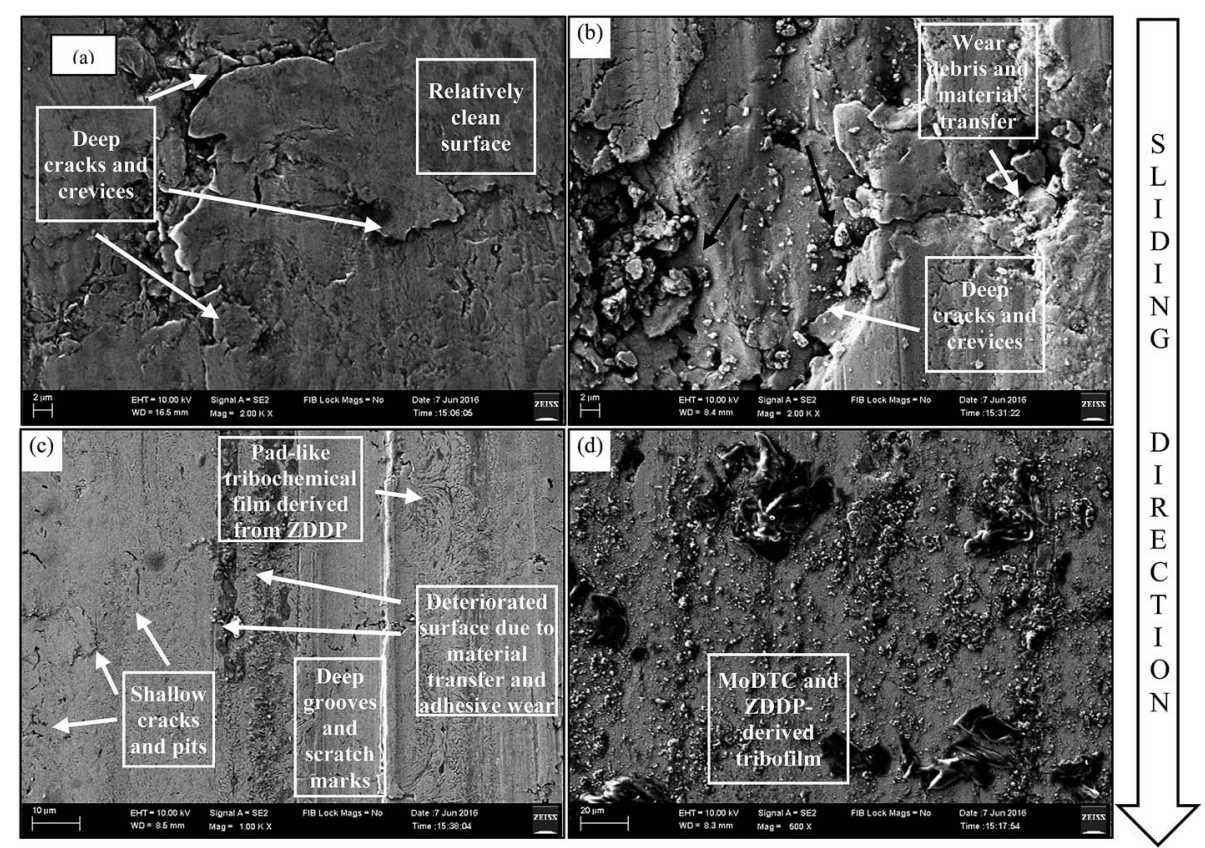

Fig. 17 SEM images of the cast iron pins in the case of the steel/cast iron contacts in combination with (a) $P A O,(b) T M P$, (c) $P+G+M+Z$, and (d) $T+G M+Z$ 
pin surface, which resulted in extremely high wear coefficients (Fig. 17). This surface deterioration was more eloquent when the additive-free TMP was used, resulting in highest value of the wear coefficient among the steel/cast iron contacts. This behavior was not observed when the formulated lubricants were used irrespective of the base-oil type (Fig. 17c and d). The additives not only substantially reduce the wear coefficient of the pins but also result in a relatively clean and unaltered surface at the end of 2 hours of sliding. When $P+G+M+Z$ was used as a lubricant, only a few deep scratch lines were observed on the pin surface accompanied by the additive-derived tribofilm and shallow cracks. The formulated version of TMP was proven to be most effective in protecting the pin and no signs of surface deterioration were detected. As abovementioned, this improved wear performance can be attributed to the formation of a tribochemical film mostly composed of zinc compounds.

\section{Discussion}

In this study, the compatibility of conventional lubricant additives (GMO, MoDTC, and ZDDP) with the TMP and W-DLC coating was evaluated, and the tribological performance parameters were compared with those of the PAO-based lubricants and steel/steel contacts. From the results, it can be clearly seen that the TMP-based lubricants offered better extreme pressure characteristics and load-carrying capacity as compared to those containing PAO, resulting not only in low wear scar diameter values but also in higher weld loads (Tables 3 and 4). A possible justification for this behavior can be the presence of the polar and unsaturated molecules in TMP with the help of which it is adsorbs on the chemically reactive steel surfaces and provides a boundary lubricant by forming a lubricant film between interacting surfaces.

During pin-on-plate tribotesting, the additive-free TMP facilitated sliding and resulted in low friction coefficient values as compared to PAO, irrespective of the interacting surface material. This behavior was attributed to the presence of fatty acids and polar $\mathrm{COOH}$ groups in the structure of TMP, which significantly improved the reactivity and consequently improved the boundary lubricant properties of the metalcontaining surfaces (cast iron and W-DLC). ${ }^{72}$ The superior performance of bio-based oils (rapeseed oils) as compared to that of the conventional base-oils (mineral oils and PAO) in combination with the symmetrical W-DLC contacts was also reported by Krzan and his team. ${ }^{30}$ In the presence of TMP baseoil, the steel/cast iron contact resulted in highest friction coefficient, whereas the lowest value was observed when the uncoated cast iron pin was used as the counterbody against the W-DLC-coated plate (Fig. 6). The improved friction performance in the presence of the W-DLC-coated surface was attributed to the inherent low friction and anti-sticking characteristics of the DLC coating due to which the contribution of adhesion to the overall friction was reduced. ${ }^{73}$ It is reasonable to expect that the cast iron counterbody in the W-DLC/cast iron contact behaves according to the conventional lubrication mechanisms and interacts with the unsaturated and polar components of TMP, whereas this effect was not possible in the W-DLC/W-DLC contact due to the low surface energy and inferior chemical reactivity of the W-DLC coating as compared to those of cast iron. ${ }^{10}$ Another justification for lowest friction coefficient value of the W-DLC/cast iron contact in combination with additivefree TMP could be the graphitization of the W-DLC coating, as shown by an increase in the $I_{\mathrm{D}} / I_{\mathrm{G}}$ ratio from 0.840 to 0.967 , whereas this effect was not seen in the symmetrical W-DLC contact (Fig. 9 and 10). It is mentioned in the literature that the structural transformation of the DLC coatings from a diamond to graphite phase results in improved friction performance due to the planar structure and low shear strength of graphite. ${ }^{74}$ If we compare the transient friction of additive-free TMP, we can clearly see a decrease in the friction coefficient value after 70 minutes of sliding in the case of the W-DLC/cast iron contact due to graphitization, whereas this behavior was not seen in the symmetrical W-DLC and steel/cast iron contact (Fig. 5).

Contrary to the friction results, additive-free TMP results in higher wear coefficients when compared to PAO irrespective of the interacting surface materials (Fig. 7). This difference in the wear characteristics was more pronounced in the W-DLC/cast iron contact. It is widely accepted that graphitization adversely affects the structural integrity of the DLC-coatings due to which the soft graphitic layer becomes more vulnerable to excessive wearing and transfers to the counterbody, resulting in the deteriorated wear performance of the contact. ${ }^{75}$ As a result of graphitization and material transfer, high wear coefficients were observed in the W-DLC/cast iron contact as compared to those in the symmetrical W-DLC contact (Fig. 7). Transfer of the coating material from the W-DLC-coated plate to the uncoated cast iron pin was also confirmed by the EDX results (Table 6). Another justification for the high wear coefficient values observed in the presence of TMP could be the formation of organic acids due to the thermal decomposition of the esters, which chemically attacked the interacting surfaces and formed a soft oxide layer. This oxide layer possessed low shear strength, which facilitated the sliding between interacting surfaces and resulted in low friction coefficients. However, it can be easily removed from the contact, due to its weak adhesion, by the scraping action of the counterbody and reformed by further chemical reaction, resulting in accelerated wearing. ${ }^{76,77}$ High wear coefficient of the W-DLC/cast iron contact as compared to that of the symmetrical W-DLC contact can also be related to the strong affinity of carbon towards the ferrous materials to form a covalent bond due to which material was transferred from the W-DLC-coated plate and diffused onto the uncoated cast iron pin. ${ }^{46}$ In an experimental investigation, Kalin et al. also observed the excessive wearing of the interacting surfaces in the $\mathrm{W}$-DLC/steel contact as compared to that in the W-DLC/W-DLC contact when additive-free sunflower was used as the lubricant. ${ }^{10}$

An improvement in the tribological performance of all the contacts was observed when the formulated lubricants were used. This behavior was attributed to graphitization of the WDLC-coating, elimination of the adhesive wear, and/or tribochemical interactions between the additives and interacting surfaces. ${ }^{29}$ The only exception to this finding was witnessed 
when $\mathrm{T}+\mathrm{G}+\mathrm{M}+\mathrm{Z}$ was used as the lubricant in combination with the W-DLC/cast iron contact since higher friction coefficient was observed as compared to that for the additive-free TMP (Fig. 6). This deterioration in the friction characteristics of the W-DLC/cast iron contact in the presence of $\mathrm{T}+\mathrm{G}+\mathrm{M}+\mathrm{Z}$ was attributed to the suppression of graphitization due to the presence of the additives in the formulation. As a result, the $I_{\mathrm{D}} /$ $I_{\mathrm{G}}$ ratio was reduced from 0.840 to 0.792 , whereas it was increased from 0.840 to 0.967 when additive-free TMP was used (Fig. 8 and 10). It is mentioned in the literature that additives suppress the graphitization of DLC coatings by passivating the dangling carbon bonds in the DLC coatings, resulting in increased friction between interacting surfaces. ${ }^{78}$ A similar increase in the friction coefficient value of the W-DLC/steel contact was also observed by other researchers when additivecontaining sunflower oil was used as the lubricant instead of its additive-free sunflower oil. ${ }^{10}$ On the other hand, the friction coefficient of the W-DLC/cast iron contact was reduced from 0.132 to 0.059 when $\mathrm{P}+\mathrm{G}+\mathrm{M}+\mathrm{Z}$ was used as a lubricant instead of additive-free PAO. This improved friction performance of $\mathrm{P}+\mathrm{G}+\mathrm{M}+\mathrm{Z}$ was attributed to the formation of $\mathrm{MOS}_{2}$ and $\mathrm{WS}_{2}$ as a result of the tribochemical interactions between MoDTC and interacting surfaces (Fig. 11b). The reported studies have proven the ability of $\mathrm{WS}_{2}$ to remarkably reduce the friction between interacting surfaces. ${ }^{33}$ Although the presence of $\mathrm{MoS}_{2}$ was also witnessed to some extent with $\mathrm{T}+\mathrm{G}+\mathrm{M}+\mathrm{Z}$, no signs of $\mathrm{WS}_{2}$ were observed in the narrow Raman spectra. The presence of molybdenum and sulfur in lower concentrations on the uncoated cast iron pin after 2 hours of sliding against the $\mathrm{W}$ DLC-coated plate in the presence of $\mathrm{T}+\mathrm{G}+\mathrm{M}+\mathrm{Z}$ instead of $\mathrm{P}+$ $\mathrm{G}+\mathrm{M}+\mathrm{Z}$ suggest different levels of the tribochemical interactions between the same additives and interacting surfaces when mixed with different base oils. This phenomenon is explained by the competition between the polar components of TMP and the polar additive-derived compounds for the same space and active sites available on the interacting surfaces. ${ }^{30}$ Another justification could be the removal of MoDTC and the GMOderived tribofilm due to the detergent action of the metallic soap formed on the contact due to the chemical attack of TMP on the interacting surfaces. ${ }^{79}$

Contrary to the friction results, the formulated version of TMP proved to be more effective in mitigating the wear of the interacting surfaces as compared to $\mathrm{P}+\mathrm{G}+\mathrm{M}+\mathrm{Z}$. A number of scratch lines and pitting wear were observed on the W-DLCcoated pins when $\mathrm{P}+\mathrm{G}+\mathrm{M}+\mathrm{Z}$ was used as the lubricant due to the abrasive action of wear debris and adhesion between interacting surfaces. As a result, some of the top W-DLC coating was removed and the $\mathrm{CrN}$ interlayer and ferrous substrate were exposed (Table 5 and Fig. 15). A possible justification for this difference in wear behavior may be the presence of ZDDPderived tribocompounds in higher concentrations on the contact and a lower extent of graphitization when $\mathrm{T}+\mathrm{G}+\mathrm{M}+\mathrm{Z}$ was used as the lubricant (Fig. 10 and Table 5). It is mentioned in the literature that ZDDP protects the surfaces from oxidation and excessive wear by utilizing oxygen and forming iron compounds such as iron sulphide and iron phosphate. ${ }^{77}$ This observation shows that different wear mechanisms and tribochemical reactions occurred on the W-DLC/W-DLC and WDLC/cast iron contacts when same additives were used in combination with PAO and TMP, resulting in different tribological behaviour. ${ }^{10}$ Difference in the morphology and chemical nature of the additive-derived tribofilms was also observed by Kalin and his team when they separately mixed conventional lubricant additives with paraffinic mineral oil and sunflower oil and used them in combination with symmetrical and asymmetrical W-DLC contacts. ${ }^{10}$ They observed a soft and plastically deformed tribochemical layer on the W-DLC/steel contact when the formulated version of mineral oil was used as the lubricant, whereas the tribofilm of the additive-containing sunflower oil was more brittle in nature. Another important conclusion, which can be drawn from the results, is that a definite synergistic correlation may exist between the base oil and additives to assure tribologically beneficial friction-induced physical and chemical interactions between the additives and the interacting surfaces.

\section{Conclusions}

In this study, a comparison of the tribological performance of PAO and TMP-based lubricants in combination with symmetrical (W-DLC/W-DLC) and asymmetrical (W-DLC/cast iron) WDLC contacts was carried out. The important conclusions, which can be drawn from experimental results, are as follows.

- The viscosity index of TMP is 1.5 times greater as compared to that of PAO, which shows that its viscosity is more stable over a wide range of temperature. Other physicochemical properties, such as the kinematic viscosity and density, of both base-oils were comparable.

- The extreme pressure characteristics and load carrying capacity of TMP was proven to be superior as compared to that of PAO. Although the LNSL and ISL of both base-oils were the same in the additive-free state, compared to PAO, TMP was able to carry $10 \mathrm{~kg}$ more load without welding of the interacting surfaces. The formulated version of TMP showed improved extreme pressure characteristics at medium and high values of applied load, whereas the additives seemed to be ineffective at lower values of the applied load.

- The additive-free TMP demonstrated better friction performance as compared to PAO in all contact types due to its unsaturated and polar structure as a result of which it is adsorbed on the interacting surfaces. However, additive-free TMP was not able to provide sufficient boundary lubrication/ wear protection and resulted in high wear coefficients values as compared to PAO.

- A significant improvement in the tribological performance was observed when the W-DLC-coated surfaces were used instead of the uncoated-ones, especially when the additive-free base-oils were used. Lowest friction coefficient values were obtained with the W-DLC/cast iron contacts, whereas extreme wear resistance of contact was observed when both surfaces were coated with the W-DLC coating irrespective of the lubricant formulation.

- Graphitization of the W-DLC-coated plates was observed when the formulated lubricants were used; however, this effect 
was not seen in the case of additive-free lubricants. The only exception to this finding was the W-DLC/cast iron contact in the presence of additive-free TMP. The influence of the base-oil type was not seen in the extent of graphitization, but increase in the degree of graphitization was realized in the presence of ferrous counterbodies.

- Although tribochemical interactions between the W-DLCcoated surfaces and additives were seen to some extent even in the absence of a ferrous-counterbody, a higher concentration of additive-derived elements was seen on the pin surface in the case of the W-DLC/cast iron and steel/cast iron contacts.

- Conventional additives, such as GMO, MoDTC, and ZDDP, which are actually optimized for conventional base-oils and materials, were also proved to be effective in TMP and resulted in improved tribological performance of the W-DLC contacts, especially of those involving a ferrous counterbody.

\section{Acknowledgements}

The authors would like to acknowledge the University of Malaya and Malaysian Ministry of Higher Education (MOHE) for funding this research through the High Impact Research Chancellory grant project titled "Development of Alternative and Renewable Energy Carrier”, Grant Number: UM.C/HIR/ MOHE/ENG/60, FRGS Grant FP-007-2014A and International Scientific Partnership Program (Ref no. ISPP\#0092) at King Saud University (KSU), Saudi Arabia.

\section{References}

1 World lubricant (2015), http://www.freedoniagroup.com.

2 L. Pop, C. Puşcaş, G. Bandur, G. Vlase and R. Nuţiu, Basestock Oils for Lubricants from Mixtures of Corn Oil and Synthetic Diesters, J. Am. Oil Chem. Soc., 2007, 85(1), 71-76.

3 X. Feng and Y. Xia, Tribological properties of Ti-doped DLC coatings under ionic liquids lubricated conditions, Appl. Surf. Sci., 2012, 258(7), 2433-2438.

4 H. M. Mobarak, E. Niza Mohamad, H. H. Masjuki, M. A. Kalam, K. A. H. Al Mahmud, M. Habibullah and A. M. Ashraful, The prospects of biolubricants as alternatives in automotive applications, Renewable Sustainable Energy Rev., 2014, 33, 34-43.

5 H. M. Mobarak, H. H. Masjuki, E. N. Mohamad, M. A. Kalam, H. K. Rashedul, M. M. Rashed and M. Habibullah, Tribological properties of amorphous hydrogenated (a-C:H) and hydrogen-free tetrahedral (ta-C) diamond-like carbon coatings under jatropha biodegradable lubricating oil at different temperatures, Appl. Surf. Sci., 2014, 317, 581-592.

$6 \mathrm{~J}$. McNutt and Q. He, Development of biolubricants from vegetable oils via chemical modification, J. Ind. Eng. Chem., 2016, 1-12.

7 Q. Zeng, O. Eryilmaz and A. Erdemir, Superlubricity of the DLC films-related friction system at elevated temperature, RSC Adv., 2015, 5(113), 93147-93154.

8 R. Zahid, H. H. Masjuki, M. Varman, R. Mufti, M. A. Kalam and M. Gulzar, Effect of Lubricant Formulations on the
Tribological Performance of Self-Mated Doped DLC Contacts: A Review, Tribol. Lett., 2015, 58(2), 1-28.

9 J. Barriga, M. Kalin, K. V. Acker, K. Vercammen, A. Ortega and L. Leiaristi, Tribological performance of titanium doped and pure DLC coatings combined with a synthetic bio-lubricant, Wear, 2006, 261(1), 9-14.

$10 \mathrm{M}$. Kalin and J. Vižintin, A comparison of the tribological behaviour of steel/steel, steel/DLC and DLC/DLC contacts when lubricated with mineral and biodegradable oils, Wear, 2006, 261(1), 22-31.

11 S. Z. Erhan, B. K. Sharma and J. M. Perez, Oxidation and low temperature stability of vegetable oil-based lubricants, Ind. Crops Prod., 2006, 24(3), 292-299.

12 Z. Liu, B. K. Sharma, S. Z. Erhan, A. Biswas, R. Wang and T. P. Schuman, Oxidation and low temperature stability of polymerized soybean oil-based lubricants, Thermochim. Acta, 2015, 601, 9-16.

13 B. K. Sharma, A. Adhvaryu and S. Z. Erhan, Friction and wear behavior of thioether hydroxy vegetable oil, Tribol. Int., 2009, 42(2), 353-358.

14 L. Wu, Y. Zhang, G. Yang, S. Zhang, L. Yu and P. Zhang, Tribological properties of oleic acid-modified zinc oxide nanoparticles as the lubricant additive in poly-alpha olefin and diisooctyl sebacate base oils, $R S C A d v$., 2016, 6(74), 69836-69844.

15 H. Wagner, R. Luther and T. Mang, Lubricant base fluids based on renewable raw materials: their catalytic manufacture and modification, Appl. Catal., A, 2001, 221(1), 429-442.

16 H. A. Hamid, R. Yunus, U. Rashid, T. S. Choong and H. Ala'a, Synthesis of palm oil-based trimethylolpropane ester as potential biolubricant: chemical kinetics modeling, Chem. Eng. J., 2012, 200, 532-540.

17 R. Yunus, A. Fakhru'l-Razi, T. L. Ooi, S. E. Iyuke and J. M. Perez, Lubrication properties of trimethylolpropane esters based on palm oil and palm kernel oils, Eur. J. Lipid Sci. Technol., 2004, 106(1), 52-60.

18 E. Uosukainen, Y.-Y. Linko, M. Lämsä, T. Tervakangas and P. Linko, Transesterification of trimethylolpropane and rapeseed oil methyl ester to environmentally acceptable lubricants, J. Am. Oil Chem. Soc., 1998, 75(11), 1557-1563.

19 J. Salimon, N. Salih and E. Yousif, Synthesis, characterization and physicochemical properties of oleic acid ether derivatives as biolubricant basestocks, J. Oleo Sci., 2011, 60(12), 613-618.

20 L. García-Zapateiro, J. Franco, C. Valencia, M. Delgado, C. Gallegos and M. Ruiz-Méndez, Chemical, thermal and viscous characterization of high-oleic sunflower and olive pomace acid oils and derived estolides, Grasas Aceites, 2013, 64(5), 497-508.

21 L. García-Zapateiro, M. Delgado, J. Franco, C. Valencia, M. Ruiz-Méndez, R. Garcés and C. Gallegos, Oleins as a source of estolides for biolubricant applications, Grasas Aceites, 2010, 61(2), 171-174.

22 S. Soni and M. Agarwal, Lubricants from renewable energy sources-a review, Green Chem. Lett. Rev., 2014, 7(4), 359382. 
23 T. Saurabh, M. Patnaik, S. Bhagt and V. Renge, Epoxidation of vegetable oils: a review, Int. J. Adv. Eng. Technol, 2011, 2, 491-501.

24 K. M. Doll, B. K. Sharma and S. Z. Erhan, Friction reducing properties and stability of epoxidized oleochemicals, Clean: Soil, Air, Water, 2008, 36(8), 700-705.

25 A. K. Somidi, R. V. Sharma and A. K. Dalai, Synthesis of Epoxidized Canola Oil Using a Sulfated-SnO $\mathrm{S}_{2}$ Catalyst, Ind. Eng. Chem. Res., 2014, 53(49), 18668-18677.

26 G. Gorla, S. M. Kour, K. V. Padmaja, M. S. Karuna and R. B. Prasad, Preparation and properties of lubricant base stocks from epoxidized karanja oil and its alkyl esters, Ind. Eng. Chem. Res., 2013, 52(47), 1659816605.

27 S. McArdle, T. Curtin and J. Leahy, Hydrogenation of sunflower oil over platinum supported on silica catalysts: preparation, characterisation and catalytic activity, Appl. Catal., A, 2010, 382(2), 332-338.

28 M. W. Balakos and E. E. Hernandez, Catalyst characteristics and performance in edible oil hydrogenation, Catal. Today, 1997, 35(4), 415-425.

29 M. Kalin, J. Vižintin, K. Vercammen, J. Barriga and A. Arnšek, The lubrication of DLC coatings with mineral and biodegradable oils having different polar and saturation characteristics, Surf. Coat. Technol., 2006, 200(14-15), 4515-4522.

30 B. Kržan, F. Novotny-Farkas and J. Vižintin, Tribological behavior of tungsten-doped DLC coating under oil lubrication, Tribol. Int., 2009, 42(2), 229-235.

31 K. Al Mahmud, M. Kalam, H. Masjuki and M. Abdollah, Tribological Study of a Tetrahedral Diamond-Like Carbon Coating under Vegetable Oil-Based Lubricated Condition, Tribol. Trans., 2015, 58(5), 907-913.

32 K. Al Mahmud, M. Varman, M. Kalam, H. Masjuki, H. Mobarak and N. Zulkifli, Tribological characteristics of amorphous hydrogenated $(\mathrm{a}-\mathrm{C}: \mathrm{H})$ and tetrahedral (ta-C) diamond-like carbon coating at different test temperatures in the presence of commercial lubricating oil, Surf. Coat. Technol., 2014, 245, 133-147.

33 M. Ratoi, V. B. Niste and J. Zekonyte, WS2 nanoparticlespotential replacement for ZDDP and friction modifier additives, RSC Adv., 2014, 4(41), 21238.

34 Standard, A., D2783-03, Standard test method for measurement of extreme-pressure properties of lubricating fluids (four-ball method), West Conshohocken, PA: ASTM International, 2009.

35 J. Cui, L. Qiang, B. Zhang, X. Ling, T. Yang and J. Zhang, Mechanical and tribological properties of Ti-DLC films with different $\mathrm{Ti}$ content by magnetron sputtering technique, Appl. Surf. Sci., 2012, 258(12), 5025-5030.

36 B. Vengudusamy, J. H. Green, G. D. Lamb and H. A. Spikes, Tribological properties of tribofilms formed from ZDDP in DLC/DLC and DLC/steel contacts, Tribol. Int., 2011, 44(2), 165-174.

37 B. Vengudusamy, R. A. Mufti, G. D. Lamb, J. H. Green and H. A. Spikes, Friction properties of DLC/DLC contacts in base oil, Tribol. Int., 2011, 44(7-8), 922-932.
38 B. Vengudusamy, J. H. Green, G. D. Lamb and H. A. Spikes, Behaviour of MoDTC in DLC/DLC and DLC/steel contacts, Tribol. Int., 2012, 54, 68-76.

39 B. Vengudusamy, J. H. Green, G. D. Lamb and H. A. Spikes, Durability of ZDDP Tribofilms Formed in DLC/DLC Contacts, Tribol. Lett., 2013, 51(3), 469-478.

40 M. Kalin, E. Roman, L. Ožbolt and J. Vižintin, Metal-doped (Ti, WC) diamond-like-carbon coatings: reactions with extreme-pressure oil additives under tribological and static conditions, Thin Solid Films, 2010, 518(15), 4336-4344.

41 M. Kalin, J. Vižintin, J. Barriga, K. Vercammen, K. Van Acker and A. Arnšek, The effect of doping elements and oil additives on the tribological performance of boundarylubricated DLC/DLC contacts, Tribol. Lett., 2004, 17(4), 679-688.

42 B. Vengudusamy, J. H. Green, G. D. Lamb and H. A. Spikes, Influence of hydrogen and tungsten concentration on the tribological properties of DLC/DLC contacts with ZDDP, Wear, 2013, 298-299, 109-119.

43 G. Stachowiak and A. Batchelor, Boundary and Extreme Pressure Lubrication, in Engineering Tribology, ButterworthHeinemann, Boston, 4th edn, 2014, ch. 8, pp. 371-428.

44 H. A. Tasdemir, M. Wakayama, T. Tokoroyama, H. Kousaka, N. Umehara, Y. Mabuchi and T. Higuchi, Ultra-low friction of tetrahedral amorphous diamond-like carbon (ta-C DLC) under boundary lubrication in poly alpha-olefin (PAO) with additives, Tribol. Int., 2013, 65, 286-294.

45 H. Abdullah Tasdemir, M. Wakayama, T. Tokoroyama, H. Kousaka, N. Umehara, Y. Mabuchi and T. Higuchi, The effect of oil temperature and additive concentration on the wear of non-hydrogenated DLC coating, Tribol. Int., 2014, 65-71.

46 H. Abdullah Tasdemir, M. Wakayama, T. Tokoroyama, H. Kousaka, N. Umehara, Y. Mabuchi and T. Higuchi, Wear behaviour of tetrahedral amorphous diamond-like carbon (ta-C DLC) in additive containing lubricants, Wear, 2013, 307(1-2), 1-9.

47 M. Kalin, E. Roman and J. Vižintin, The effect of temperature on the tribological mechanisms and reactivity of hydrogenated, amorphous diamond-like carbon coatings under oil-lubricated conditions, Thin Solid Films, 2007, 515(7-8), 3644-3652.

$48 \mathrm{~S}$. Neuville and A. Matthews, A perspective on the optimisation of hard carbon and related coatings for engineering applications, Thin Solid Films, 2007, 515(17), 6619-6653.

49 Y. M. Foong, A. T. T. Koh, J. Hsieh and D. H. C. Chua, A comparative study on as-deposited and in situ oxidized $\mathrm{ZnO}$ /diamondlike carbon (DLC) nanocomposite by pulsed laser deposition technique, J. Mater. Res., 2011, 25(05), 899-909.

50 G. Dumitru, V. Romano, H. P. Weber, S. Pimenov, T. Kononenko, M. Sentis, J. Hermann and S. Bruneau, Femtosecond laser ablation of diamond-like carbon films, Appl. Surf. Sci., 2004, 222(1-4), 226-233.

51 K. A. H. Al Mahmud, M. Varman, M. A. Kalam, H. H. Masjuki, H. M. Mobarak and N. W. M. Zulkifli, 
Tribological characteristics of amorphous hydrogenated (a$\mathrm{C}: \mathrm{H})$ and tetrahedral (ta-C) diamond-like carbon coating at different test temperatures in the presence of commercial lubricating oil, Surf. Coat. Technol., 2014, 133-147.

52 K. K. Mistry, A. Morina and A. Neville, A tribochemical evaluation of a WC-DLC coating in EP lubrication conditions, Wear, 2011, 271(9-10), 1739-1744.

53 D.-W. Kim and K.-W. Kim, Effects of sliding velocity and ambient temperature on the friction and wear of a boundary-lubricated, multi-layered DLC coating, Wear, 2014, 133-147.

54 L. Wang, L. Bai, Z. Lu, G. Zhang and Z. Wu, Influence of Load on the Tribological Behavior of a-C Films: Experiment and Calculation Coupling, Tribol. Lett., 2013, 52(3), 469-475.

55 J. H. Ouyang and S. Sasaki, Friction and wear characteristics of a Ti-containing diamond-like carbon coating with an SRV tester at high contact load and elevated temperature, Surf. Coat. Technol., 2005, 195(2-3), 234-244.

56 A. Ferrari and J. Robertson, Interpretation of Raman spectra of disordered and amorphous carbon, Phys. Rev. B: Condens. Matter Mater. Phys., 2000, 61(20), 14095.

57 L. Zhang, F. Wang, L. Qiang, K. Gao, B. Zhang and J. Zhang, Recent advances in the mechanical and tribological properties of fluorine-containing DLC films, RSC Adv., 2015, 5(13), 9635-9649.

$58 \mathrm{~K}$. Komori and N. Umehara, Effect of surface morphology of diamond-like carbon coating on friction, wear behavior and tribo-chemical reactions under engine-oil lubricated condition, Tribol. Int., 2014, 100-109.

59 W. Yue, C. Liu, Z. Fu, C. Wang, H. Huang and J. Liu, Synergistic effects between sulfurized W-DLC coating and MoDTC lubricating additive for improvement of tribological performance, Tribol. Int., 2013, 62, 117-123.

60 T. Shen, D. Wang, J. Yun, Q. Liu, X. Liu and Z. Peng, Mechanical stability and rheology of lithium-calciumbased grease containing ZDDP, RSC Adv., 2016, 6(14), 11637-11647.

$61 \mathrm{~K}$. Meyer, Characterization of the structure of binary zinc ultraphosphate glasses by infrared and Raman spectroscopy, J. Non-Cryst. Solids, 1997, 209(3), 227-239.

62 R. Zahid, M. B. H. Hassan, M. Varman, R. A. Mufti, M. A. Kalam, N. W. B. M. Zulkifli and M. Gulzar, A Review on Effects of Lubricant Formulations on Tribological Performance and Boundary Lubrication Mechanisms of Non-Doped DLC/DLC Contacts, Crit. Rev. Solid State Mater. Sci., 2016, 1-28.

63 S. Equey, S. Roos, U. Mueller, R. Hauert, N. D. Spencer and R. Crockett, Reactions of zinc-free anti-wear additives in DLC/DLC and steel/steel contacts, Tribol. Int., 2008, 41(11), 1090-1096.

64 S. Equey, S. Roos, U. Mueller, R. Hauert, N. D. Spencer and R. Crockett, Tribofilm formation from ZnDTP on diamondlike carbon, Wear, 2008, 264(3-4), 316-321.

65 D. N. Khaemba, A. Neville and A. Morina, New insights on the decomposition mechanism of Molybdenum
DialkyldiThioCarbamate (MoDTC): a Raman spectroscopic study, RSC Adv., 2016, 6(45), 38637-38646.

66 B. C. Windom, W. G. Sawyer and D. W. Hahn, A Raman Spectroscopic Study of $\mathrm{MoS}_{2}$ and $\mathrm{MoO}_{3}$ : Applications to Tribological Systems, Tribol. Lett., 2011, 42(3), 301-310.

67 H. Spikes, The history and mechanisms of ZDDP, Tribol. Lett., 2004, 17(3), 469-489.

68 H. Abdullah Tasdemir, T. Tokoroyama, H. Kousaka, N. Umehara and Y. Mabuchi, Influence of zinc dialkyldithiophosphate tribofilm formation on the tribological performance of self-mated diamond-like carbon contacts under boundary lubrication, Thin Solid Films, 2014, 562, 389-397.

69 N. W. M. Zulkifli, S. S. N. Azman, M. A. Kalam, H. H. Masjuki, R. Yunus and M. Gulzar, Lubricity of bio-based lubricant derived from different chemically modified fatty acid methyl ester, Tribol. Int., 2016, 93, 555-562.

70 N. W. M. Zulkifli, M. A. Kalam, H. H. Masjuki, M. Shahabuddin and R. Yunus, Wear prevention characteristics of a palm oil-based TMP (trimethylolpropane) ester as an engine lubricant, Energy, 2013, 54, 167-173.

71 T. Quinn, J. Sullivan and D. Rowson, Origins and development of oxidational wear at low ambient temperatures, Wear, 1984, 94(2), 175-191.

72 K. Vercammen, K. Van Acker, A. Vanhulsel, J. Barriga, A. Arnsek, M. Kalin and J. Meneve, Tribological behaviour of DLC coatings in combination with biodegradable lubricants, Tribol. Int., 2004, 37(11-12), 983-989.

73 M. Kalin and J. Vižintin, The tribological performance of DLC-coated gears lubricated with biodegradable oil in various pinion/gear material combinations, Wear, 2005, 259(7-12), 1270-1280.

74 L. Yang, A. Neville, A. Brown, P. Ransom and A. Morina, Friction reduction mechanisms in boundary lubricated $\mathrm{W}$ doped DLC coatings, Tribol. Int., 2014, 70, 26-33.

75 R. Zahid, H. H. Masjuki, M. Varman, M. A. Kalam, R. A. Mufti, N. W. B. M. Zulkifli, M. Gulzar and S. S. B. N. Azman, Influence of intrinsic and extrinsic conditions on the tribological characteristics of diamondlike carbon coatings: a review, J. Mater. Res., 2016, 1-23.

76 B. Kržan and J. Vižintin, Tribological properties of an environmentally adopted universal tractor transmission oil based on vegetable oil, Tribol. Int., 2003, 36(11), 827-833.

77 N. H. Jayadas, K. Prabhakaran Nair and G. Ajithkumar, Tribological evaluation of coconut oil as an environmentfriendly lubricant, Tribol. Int., 2007, 40(2), 350-354.

78 S. Kosarieh, A. Morina, E. Lainé, J. Flemming and A. Neville, Tribological performance and tribochemical processes in a DLC/steel system when lubricated in a fully formulated oil and base oil, Surf. Coat. Technol., 2013, 217, 1-12.

79 S. Shimada, H. Tanaka, M. Higuchi, T. Yamaguchi, S. Honda and K. Obata, Thermo-chemical wear mechanism of diamond tool in machining of ferrous metals, CIRP Ann. Manuf. Technol., 2004, 53(1), 57-60. 